\title{
Senescence Inducer Shikonin ROS-Dependently Suppressed Lung Cancer Progression
}

\begin{abstract}
Hongming Zheng ${ }^{1 \dagger}$, Qiuju Huang ${ }^{1 t}$, Suchao Huang ${ }^{1}$, Xia Yang ${ }^{1}$, Ting Zhu', Wensheng Wang ${ }^{1}$, Haojia Wang ${ }^{1}$, Shugui He ${ }^{1}$, Liyan $\mathrm{Ji}^{1}$, Ying Wang ${ }^{1}$, Xiaoxiao Qi ${ }^{1}$, Zhongqiu Liu ${ }^{1,2 *}$ and Linlin Lu ${ }^{1,2 *}$
\end{abstract}

1 International Institute for Translational Chinese Medicine, Guangzhou University of Chinese Medicine, Guangzhou, China, ${ }^{2}$ State Key Laboratory of Quality Research in Chinese Medicine, Macau University of Science and Technology, Taipa, Macau

Lung adenocarcinoma ( $\angle A C)$, predominant subclassfication of lung cancer, leads high incidence and mortality annually worldwide. During the premalignant transition from lung adenomas to LAC, cellular senescence is regard as a critical physiological barrier against tumor progression. Nevertheless, the role of senescence in tumorigenesis

Edited by:

Vincent Kam Wai Wong, Macau University of Science and Technology, Macau

Reviewed by: William Chi-Shing Tai, The Hong Kong Polytechnic

University, Hong Kong

W. L. Wendy Hsiao, Macau University of Science

and Technology, Macau

${ }^{*}$ Correspondence: Zhongqiu Liu liuzq@gzucm.edu.cn Linlin Lu

Illu@gzucm.edu.cn

${ }^{\dagger}$ These authors have contributed equally to this work.

Specialty section: This article was submitted to Ethnopharmacology,

a section of the journal Frontiers in Pharmacology

Received: 09 November 2017 Accepted: 30 April 2018 Published: 23 May 2018

Citation:

Zheng H, Huang Q, Huang S, Yang $X$, Zhu $T$, Wang $W$, Wang $H$, He S, Ji L, Wang Y, Qi X, Liu Z and

Lu L (2018) Senescence Inducer Shikonin ROS-Dependently Suppressed Lung Cancer Progression.

Front. Pharmacol. 9:519. doi: 10.3389/fphar.2018.00519 is controversial and few senescence inducers are extensively determined. In this study, we used two classical cell lines A549 and H1299 and two NSCLC xenograft models on Balb/c-nude mice to reveal the pro-senescence effects of shikonin and the corresponding underlying mechanism in LAC. Shikonin, a pure compound isolated from the herbal medicine Lithospermum erythrorhizon, remarkably stimulated cellular senescence including increased SAHF formation, enlarged cellular morphology, and induced $S A-\beta-G a l$ positive staining. Further mechanism study revealed that the prosenescence effect of shikonin was dependent on the increased intercellular ROS generation, which subsequently triggered DNA damage-p53/p2 $1^{\text {waf }}$ axis without activating oncogenes such as Ras and MEK-1. Meanwhile, Kdm2b, an H3K36me2specific demethylase effectively suppressed ROS generation, was also notably suppressed by shikonin treatment. Moreover, shikonin at $10 \mathrm{mg} / \mathrm{kg}$ significantly inhibited tumor weights by $55.84 \%$ and $50.98 \%$ in A549 and H1299 xenograft model, respectively $(P<0.05)$ through activating cellular senescence. Our study suggested that shikonin, a ROS-dependent senescence inducer, could serve as a promising agent for further lung cancer treatment.

Keywords: shikonin, lung cancer, senescence, ROS, DNA damage

\section{INTRODUCTION}

Lung adenocarcinoma, predominantly developed from pre-malignancy lung adenomas, leads estimate 910,000 incidence and 800,000 mortality annually worldwide (Curado et al., 2008; Ferlay et al., 2015). Pathological study revealed that cellular senescence, an intrinsic and irreversible suicide program, is accelerated in lung adenomas while strikingly diminished in LAC, suggesting

Abbreviations: DDR, DNA damage response; EdU, 5-ethynyl-2'-deoxyuridine; LAC, Lung adenocarcinoma; MTT, 3-(4,5dimethylthiazol-2-yl)-2,5-diphenyltetrazolium bromide; NAC, $N$-Acetyl-L-Cysteine; OIS, oncogene-induced senescence; PI, propidium iodide; PICS, PTEN loss-induced cellular senescence; PMSF, phenylmethanesulfonyl fluoride; ROS, reactive oxygen species; RS, replicative senescence; SA- $\beta$-Gal, senescence-associated $\beta$-galactosidase; SAHF, senescence-associated heterochromatin foci; SHK, shikonin; TSG, tumor suppressor genes. 
senescence is a critical physiological barrier against tumor progression (Collado et al., 2005). Furthermore, during chemotherapy and radiation, a robust of senescence stimulation is also found to synergistically determine cancer prognosis and systemic toxicity. For instance, loss of $\mathrm{p} 14^{\mathrm{ARF}}$-dependent senescence correlated with poor outcome of non-small cell lung cancer (Han et al., 2017). Meanwhile, parallel to apoptosis activation, chemotherapy-induced senescence predominately triggered regenerative response against systemic toxicities including bone marrow suppression and gastrointestinal toxicity (Shao et al., 2013). Due to intrinsic and primary physiological response against tumorigenesis, senescence-targeting approach were estimated to cause fewer feedback signaling alterations (Dörr et al., 2013) compared to other targeted chemotherapeutic agents such as gefitinib, afatinib, and cetuximab (Fertig et al., 2016). Moreover, "synthetic senescent interaction" could be also achieved by combining Kras activation with Cdk4 loss, Myc stimulation with Cdk2 depletion (Campaner et al., 2010; Puyol et al., 2010). Therefore, pro-senescence therapy is regarded as a novel and promising strategy for cancer eradication.

Cellular senescence, a stable proliferative arrest in normal cells, is triggered by a combination of four major mechanisms: telomere shortening-dependent replicative senescence (RS), oncogene-induced senescence (OIS), tumor suppressor gene (TSG) inactivation, as well as stress-induced senescence (Ogrunc et al., 2014). RS, also known as replicative senescence often depends on telomere dysfunction induced by replicationassociated telomere shortening (Petrova et al., 2016). OIS depends on activation or overexpression of oncogenes such as RAS and BRAF ${ }^{\mathrm{V} 600 \mathrm{E}}$ activation (Xie et al., 2015). TSG depends on tumor suppressor inactivation or loss, such as PICS (Tan et al., 2015). During each type of senescence, various phenotypes were consequently altered such as senescenceassociated $\beta$-galactosidase activity (SA- $\beta$-gal), formation of SAHF, and sustained DDR (Petrova et al., 2016). Subsequently, p53, p21 $1^{\text {waf }}$, and p16 are activated while cyclin-dependent kinases including CDK4 and CDK6 are contrarily suppressed in senescent cells (Petrova et al., 2016). Meanwhile, some of epigenetic modifiers were also involved such as $\mathrm{H} 3 \mathrm{~K} 9$ histone methyltransferase and polycomb complexes including H3K36 demethylase and H3K27 demethylase (David, 2012). Compared to other senescence mechanisms, stress-induced senescence plays a comprehensive and predominant role in tumor initiation by widely altering genomic and epigenetic landscapes. ROS, one of the earliest responses toward oxidative stress, exerts various functions even with apparently opposite outcomes. Concretely speaking, intercellular ROS accumulation effectively stimulated cell hyperproliferation via activating mitogenic pathway, whereas at the meantime, ROS contrarily suppressed DNA replication though causing DDR-p53/p21 waf signaling (Ogrunc et al., 2014). Thus, given the controversial role of ROS-induced senescence in tumorigenesis, the mechanisms underlying still need extensively investigation. At the meantime, considering the vital role of ROS in tumor initiation, developing an effective ROSdependent pro-senescence agent is also urgent need for clinical chemoprevention.
Until now, various pro-senescence agents were developed and some of them have been entered into clinical trials such as GRN163L, nutlin, and MIRA-1 (Acosta and Gil, 2012; Burchett et al., 2014). However, systemic toxicity and drug resistance greatly limited their clinical applications. SHK, a pure compound isolated from the herbal medicine Lithospermum erythrorhizon, exhibited anti-inflammatory, antitumor, and antiviral effectiveness with tolerable toxicity (Chen et al., 2002; Lu et al., 2011). Previous studies indicated that SHK could significantly inhibit lung carcinogenesis by stimulating apoptosis and arresting cell cycle (Lan et al., 2014). Meanwhile, SHK also effectively suppressed tumor metastasis via suppressing ERK1/2 signaling (Wang et al., 2013). Also, SHK shown to induce apoptosis, senescence and necrosis through up regulating p53 in A549 cells (Yeh et al., 2015). Furthermore, in gefitinib-resistance lung cancer cells, SHK was also reported to sensitize chemotherapeutic efficacy by inhibiting TrxR while activating EGFR proteasomal degradation (Li et al., 2017). However, whether SHK could trigger ROS generation in lung cancer cells is unknown, and whether SHKinduced senescence depends on ROS generation also remains unclear.

In our present study, the pro-senescence effects and mechanisms of SHK were determined in A549 and H1299 cells in vitro and xenograft models in vivo. We found that SHK significantly inhibited tumor proliferation via stimulating cellular senescence. Further mechanistic study revealed that SHK-induced senescence was dependent on ROS generation with increasing DNA damage (p-H2A.X), p53 (total and phosphorylation), and $\mathrm{p} 21^{\mathrm{waf}}$. Our study suggested that SHK, a ROS-dependent senescence inducer, could serve as a promising agent for further lung cancer treatment, and even chemoprevention.

\section{MATERIALS AND METHODS}

\section{Reagents and Cell Culture}

SHK (purity > 98\%) was purchased from Chengdu Must Biotechnology Co., Ltd. (Chengdu, China). MTT and NAC were purchased from Sigma-Aldrich (St. Louis, MO, United States). PI staining was purchased from Biosciences (BD Biosciences, Franklin Lakes, NJ, United States). $\beta$-actin, MEK-1, p53 and $\mathrm{p} 21^{\text {waf }}$ primary antibodies and HRP-conjugated secondary antibody were purchased from Santa Cruz Biotechnologies Inc. (Santa Cruz, CA, United States). Bcl-2, Bax, Rb, Cleaved Caspase3, Ras, H3K36me2, p-p53, p-H2A.X, Histone H3 and Cyclin D1 antibodies were purchased from Cell Signaling Technology Inc. (Beverly, MA, United States). Kdm2b antibody was purchased from Millipore (Burlington, MA, United States). p16 antibody was purchased from Abcam (Cambridge, United Kingdom). Specific small interfering RNA (siRNA) of p21 and riboFECTTM CP Transfection Kit (166T) were purchased from Ribobio, Co., Ltd (Guangdong, China). Two human LAC cells (A549 and H1299) were purchased from ATCC (Manassas, VA, United States). A549 and H1299 cells were maintained in RPMI1640 medium with $10 \%$ fetal bovine serum (FBS) and 1\% 
penicillin-streptomycin solution, and cultured in a humidified atmosphere at $37^{\circ} \mathrm{C}$ with $5 \% \mathrm{CO}_{2}$.

\section{MTT Assay}

Cells were seeded into 96-well plates at $2 \times 10^{3}$ cells/well. After cultured overnight, cells were treated with SHK $(0-6 \mu \mathrm{M})$ for 24, 48, and $72 \mathrm{~h}$. Cells were incubated with the MTT solution $(0.5 \mathrm{mg} / \mathrm{mL})$ at $37^{\circ} \mathrm{C}$ for $4 \mathrm{~h}$. The supernatants were replaced by dimethyl sulfoxide $(150 \mu \mathrm{L} /$ well). Then the absorbance was measured using microplate reader Victor X3 (PerkinElmer, Waltham, MA, United States) at $490 \mathrm{~nm}$. The half inhibitory concentration $\left(\mathrm{IC}_{50}\right)$ was obtained using the nonlinear regression program of GraphPad Prism 5.

\section{5-Ethynyl-2' -deoxyuridine (EdU) Assay}

EdU, a nucleoside analog of thymidine which is in corporated into DNA during active DNA synthesis, is often used to measure cell proliferation. Cells were seeded into 96 -well plates at $2 \times 10^{3}$ cells/well, and treated with SHK (1 and $2 \mu \mathrm{M}$ for A549, 0.3 and $0.6 \mu \mathrm{M}$ for $\mathrm{H} 1299$, respectively) for $72 \mathrm{~h}$. Then cells were incubated with EdU labeling medium $(50 \mu \mathrm{M})$ for $2 \mathrm{~h}$ at $37^{\circ} \mathrm{C}$ with $5 \% \mathrm{CO}_{2}$, fixed with $4 \%$ paraformaldehyde $(\mathrm{pH}=7.4)$ for $30 \mathrm{~min}$, and incubated with glycine for $5 \mathrm{~min}$. After rinsed with PBS, cells were incubated with anti-EdU working solution at room temperature for $30 \mathrm{~min}$, following with Hoechst 33342 dye $(1 \times)$ at room temperature for $30 \mathrm{~min}$. The images were captured using Leica3000B (Leica, GER). The percentages of EdU-positive cells were calculated from five random fields in two wells.

\section{Cell Cycle Analysis}

Cells were seeded into 6 -well plates at $6 \times 10^{4}$ cells/well and treated with SHK (1 and $2 \mu \mathrm{M}$ for A549, 0.3 and $0.6 \mu \mathrm{M}$ for H1299, respectively) for 72 h. Following, cells were harvested, washed twice with PBS, and fixed with $70 \%$ cold ethanol at $4^{\circ} \mathrm{C}$ overnight, then stained with PI $(50 \mu \mathrm{g} / \mathrm{mL})$ at $37^{\circ} \mathrm{C}$ for $0.5 \mathrm{~h}$ protecting from light. Cell cycle was detected by flow cytometry (BD Biosciences, San Jose, CA, United States). The results were analyzed by FlowJo 7.6 software.

\section{Detection of Senescence-Associated Heterochromatin Foci (SAHF)}

SAHF are specialized domains of facultative heterochromatinin senescent cells. 4',6-diamidino-2-phenylindole (DAPI) staining was used to observe SAHF. Cells were seeded into $15 \mathrm{~mm}$ confocal dish at $3 \times 10^{4}$ cells/well, cultured overnight, then treated with SHK (2 $\mu \mathrm{M}$ for A549 and $0.6 \mu \mathrm{M}$ for H1299, respectively) for $72 \mathrm{~h}$. After harvested, cells were fixed in $4 \%$ cold paraformaldehyde, incubated with DAPI for $10 \mathrm{~min}$. The images were captured using Leica TCS SP8 confocal microscope (Leica, GER). All images were acquired using an identical parameter time for all samples.

\section{Senescence-Associated $\beta$-Galactosidase (SA- $\beta$-Gal) Assay}

Cells were seeded into 6-well plates at $6 \times 10^{4}$ cells/well and treated with SHK (1 and $2 \mu \mathrm{M}$ for A549, 0.3 and $0.6 \mu \mathrm{M}$ for H1299, respectively) for $72 \mathrm{~h}$. Then cells were stained with SA- $\beta$-Gal in accordance to the manufacturer's procedure of Senescent Cell Histochemical Staining Kit (CST). Meanwhile, tumor tissues were frozen and sliced up $(4 \mu \mathrm{m})$. Then the frozen sections were stained immediately with SA- $\beta$-Gal in accordance to the manufacturer's procedure of Senescent Cell Histochemical Staining Kit (CST).

\section{ROS Detection}

Reactive oxygen species formation in cells was detected using Cellular Reactive Oxygen Species Detection Assay Kit (Abcam, United Kingdom), according to the manufacturer's instruction. Briefly, cells were seeded into 6 -well plates at $6 \times 10^{4}$ cells/well and treated with SHK (1 and $2 \mu \mathrm{M}$ for A549, 0.3 and $0.6 \mu \mathrm{M}$ for $\mathrm{H} 1299$, respectively) for $72 \mathrm{~h}$. Then the cells were collected and washed twice with PBS and suspended in PBS- $\mathrm{H}_{2} \mathrm{DCFDA}$ $(10 \mu \mathrm{M})$ at $37^{\circ} \mathrm{C}$ for $30 \mathrm{~min}$. After that, the fluorescence was monitored by flow cytometry.

\section{siRNA Interference}

The siRNA was used to interfere the gene and protein expressions of $\mathrm{p} 21^{\mathrm{waf}}$. The sequence of siRNA was: GAATGAGAGGTTCCTAAGA. Cells were seeded into 6well plates at $3 \times 10^{5}$ cells/well, and transfected with $50 \mathrm{nM}$ siRNA or negative control using riboFECTTM CP Transfection Kit (166T) in serum free Opti-MEM media according to the manufacturer's protocal. After $12 \mathrm{~h}$ transection, the cells were digested and seeded into new 6-well plates at a density of $1 \times 10^{5}$ cells/well, and cultured overnight, then the cells were continuously cultured with or without SHK ( $2 \mu \mathrm{M}$ for A549 and $0.6 \mu \mathrm{M}$ for H1299, respectively) for $72 \mathrm{~h}$. Finally, cells were harvested for following assay.

\section{Western Blot}

After cells were harvested, total proteins were extracted using RIPA lysis buffer and phenylmethanesulfonyl fluoride (PMSF), and quantified using Coomassie Brilliant Blue Kit (Bio-Rad, Hercules, CA, United States). Protein samples were separated by SDS-PAGE, transferred onto PVDF membranes, and blocked with $5 \%$ BSA for $1 \mathrm{~h}$, and then incubated with the primary antibodies at $4^{\circ} \mathrm{C}$ overnight, subsequently, with secondary antibodies at room temperature for $1 \mathrm{~h}$. ECL chemiluminescence reagent was applied to detect for fluorescent signals using FluorChem E (Santa Clara, CA, United States). Protein bands were quantified using Quantity One software (Bio-Rad, Hercules, CA, United States).

\section{Apoptosis Detection}

Cells were seeded into 6 -well plates at $6 \times 10^{4}$ cells/well and treated with SHK (1 and $2 \mu \mathrm{M}$ for A549, 0.3 and $0.6 \mu \mathrm{M}$ for H1299, respectively) for $72 \mathrm{~h}$. After harvested, cells were processed using the FITC annexin V/PI Apoptosis Detection Kit (BD Biosciences, United States), according to the manufacturer's protocol. After that, cell apoptosis was analyzed by the flow cytometry. 


\section{Immunofluorescence}

Cells were seeded into $15 \mathrm{~mm}$ confocal dish $3 \times 10^{4}$ cells/well, cultured overnight, then treated with SHK ( 1 and $2 \mu \mathrm{M}$ for A549, 0.3 and $0.6 \mu \mathrm{M}$ for H1299, respectively) for $72 \mathrm{~h}$. After harvested, cells were fixed in $4 \%$ cold paraformaldehyde, incubated with the primary antibodies at $4^{\circ} \mathrm{C}$ overnight, and with Alexa Fluor ${ }^{\circledR}$ conjugated secondary antibodies $(1: 500, v / v)$ at room temperature for $1 \mathrm{~h}$ protecting from light. The images were captured using Leica TCS SP8 confocal microscope (Leica, GER). All images were acquired using an identical parameter time for all samples.

\section{NSCLC Xenograft Mice Models}

Female Balb/c-nude mice (4-6 weeks, 16-20 g) were purchased from Laboratory Animal Center of Sun Yat-sen University [Guangzhou, China; License number: SCXK (Guangdong) 2016-0029], and kept in the animal facility in the SPF animal laboratory [License number: SYXK (GZ) 2014-0144] at International Institute for Translational Chinese Medicine, Guangzhou University of Chinese Medicine (Guangzhou, China). The animal experiments were approved by the Guangzhou University of Chinese Medicine Animal Care and Use Committee (Guangzhou, China), and conducted according with the ethical standards and national guidelines. For A549 xenograft model, mice were subjected to subcutaneously injection with A549 cells $\left(2.5 \times 10^{6}\right.$ cells/mouse $)$ in each right flank. Tumor volume (TV), defined based on two dimensions ( $\mathrm{L}$, long diameter; $\mathrm{W}$, wide diameter), was measured by calipers, and calculated as formula: TV $\left(\mathrm{mm}^{3}\right)=\left(\mathrm{L} \times \mathrm{W}^{2}\right) / 2$. When the tumors reached a mean volume of $50 \mathrm{~mm}^{3}$, eligible mice were randomized into four groups $(n=7)$ as following: gavage control (sterilized coin oil), afatinib $(5 \mathrm{mg} / \mathrm{kg})$, SHK $(5,10 \mathrm{mg} / \mathrm{kg})$. For H1299 xenograft model, mice were subjected to subcutaneously injection with $\mathrm{H} 1299$ cells $\left(3 \times 10^{6}\right.$ cells/mouse $)$ in each right flank. When the tumors reached a mean volume of $50 \mathrm{~mm}^{3}$, the mice were randomized into two groups $(n=7)$ as following: gavage control (sterilized coin oil), SHK $(10 \mathrm{mg} / \mathrm{kg})$. Animals received oral administration with drugs five times a week for 4 weeks. Body weights were recorded every 3 days. At the end of the experiments, mice were sacrificed, and the tumors and organs were removed and weighed for following assays.

\section{Immunohistochemistry}

Tumor tissues were fixed in $4 \%$ paraformaldehyde, embedded in paraffin, and then sliced up $(4 \mu \mathrm{m})$. Then slices were dewaxed, hydrated, and then incubated with natrium citric $(0.01 \mathrm{M})$ for antigen retrieval. Following, the slices were rinsed with PBS, and incubated with diluted anti-p-H2A.X, anti-p53 and anti-p21 overnight at $4^{\circ} \mathrm{C}$. Following steps were performed using the immunostaining kit (BOSTER Biological Technology) based on the manufacturer's instructions.

\section{Statistical Analysis}

All data were expressed as the mean \pm standard deviation (SD). Significant differences were analyzed by one-way analysis of variance (ANOVA) followed by the LSD post hoc test using SPSS 19.0 software. Statistical differences were considered significant at $p<0.05$.

\section{RESULTS}

\section{SHK Suppressed Lung Cancer Cell Proliferation via Arresting Cell Cycle at G0/G1 Phase}

To determine the cytotoxicity of SHK (Figure 1A), cell viabilities were evaluated at 24,48 , and $72 \mathrm{~h}$, respectively by MTT assay. SHK dose- and time-dependently suppressed viable cell percentages in A549 and $\mathrm{H} 1299$ cells, and the respective $\mathrm{IC}_{50}$ were $2.28 \pm 0.19$ and $0.64 \pm 0.07 \mu \mathrm{M}$ at $72 \mathrm{~h}$ (Figure 1B). Therefore, considering diverse SHK sensitivity observed in these two cells, 1 and $2 \mu \mathrm{M}$ of SHK were selected for further treatments in A549 cells, while 0.3 and $0.6 \mu \mathrm{M}$ were applied to H1299 cells according to the equivalent viability in A549 cells.

Furthermore, EdU assay and flow cytometry were performed to analyze the effect of SHK on lung cancer cell proliferation. Given the cytotoxicity of SHK found previously (Figure 1B), the average percentages of EdU fluorescence, rather than the absolute EdU-labeling cell numbers, in each treatment were analyzed accordingly (Yang et al., 2011). In contrast to the abundant EdU-positive cells observed in control (Ctrl, 0.1\% DMSO, same as follows), SHK at 1 and $2 \mu \mathrm{M}$ significantly suppressed A549 cell proliferation ratio by $44.00 \% \pm 2.22 \%$ and $84.42 \% \pm 4.57 \%$ (Figure 1C, $P<0.001$ ). Simultaneously, SHK at $2 \mu \mathrm{M}$ notably increased the percentage of A549 cells at $\mathrm{G} 0 / \mathrm{G} 1$ phase from $45.79 \% \pm 2.27 \%$ in control treatment to $54.12 \% \pm 0.10 \%$ (Figure 1D, $P<0.001$ ). Similarly, remarkable inhibition of EdU fluorescence (range 36.51-67.44\%) were also found in H1299 cells after treatment with 0.3 and $0.6 \mu \mathrm{M}$ of SHK (Figure 1C, $P<0.001$ ). And 0.3 and $0.6 \mu \mathrm{M}$ of SHK also markedly arrested H1299 cells at G0/G1 phase by $13.78 \% \pm 0.58 \%$ and $19.81 \% \pm 0.47 \%$ (Figure 1D, $P<0.001$ ). Moreover, given the significant G0/G1 arrest in A549 and H1299 cells, cyclin D1, a key protein required for progression through the G1 phase of the cell cycle (Sherr and Roberts, 2004) was further determined. Compared to control treatment, SHK at 2 and $0.6 \mu \mathrm{M}$ significantly decreased the expression of cyclin D1 by $35.21 \% \pm 8.17 \%$ and $24.25 \% \pm 5.73 \%$ in A549 and $\mathrm{H} 1299$ cells, respectively (Figure 1E, $P<0.01$ ).

\section{SHK Notably Promoted Cell Senescence in A549 and H1299 Cells}

Considering two key phenotypes of senescence, G0/G1 arrest (Lleonart et al., 2009) (Figure 1D) and cell relative enlargement (Muñoz-Espín and Serrano, 2014) (Figure 1C), were unexpectedly observed after our SHK treatments, we hypothesized that SHK might influence senescence to suppress cell proliferative capacity in A549 and H1299 cells. Thus, the effects of SHK in senescence were further determined by SAHF detection (Funayama et al., 2006) and SA- $\beta$-Gal staining (Dimri et al., 1995). 
A<smiles>CC(C)=CCC(O)C1=CC(=O)c2c(O)ccc(O)c2C1=O</smiles>

Shikonin (SHK)

C

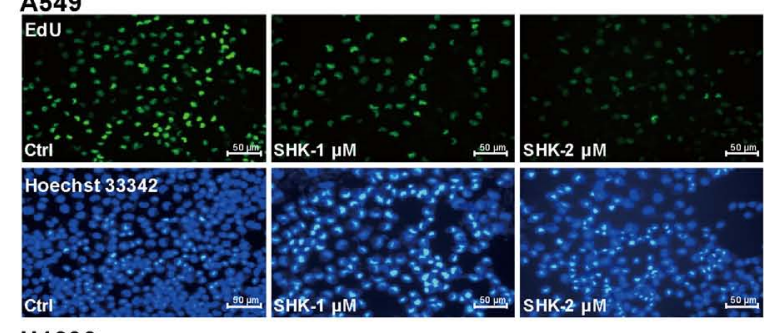

H1299
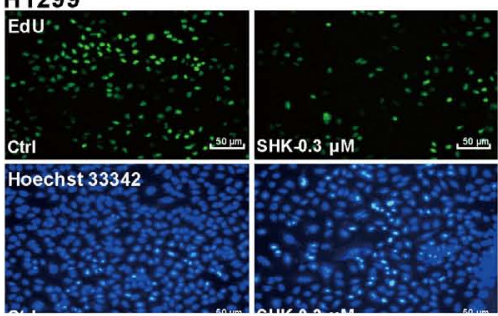

A549

D

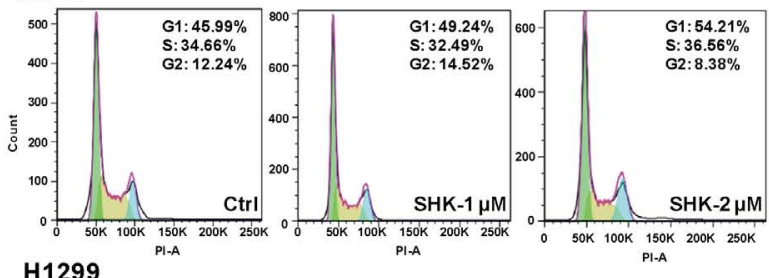

Hiso
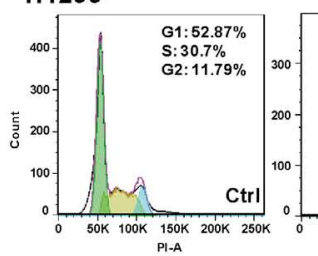

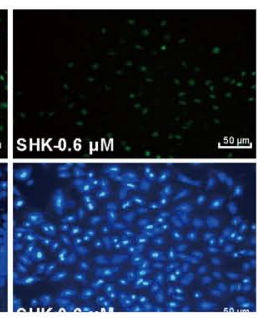

B
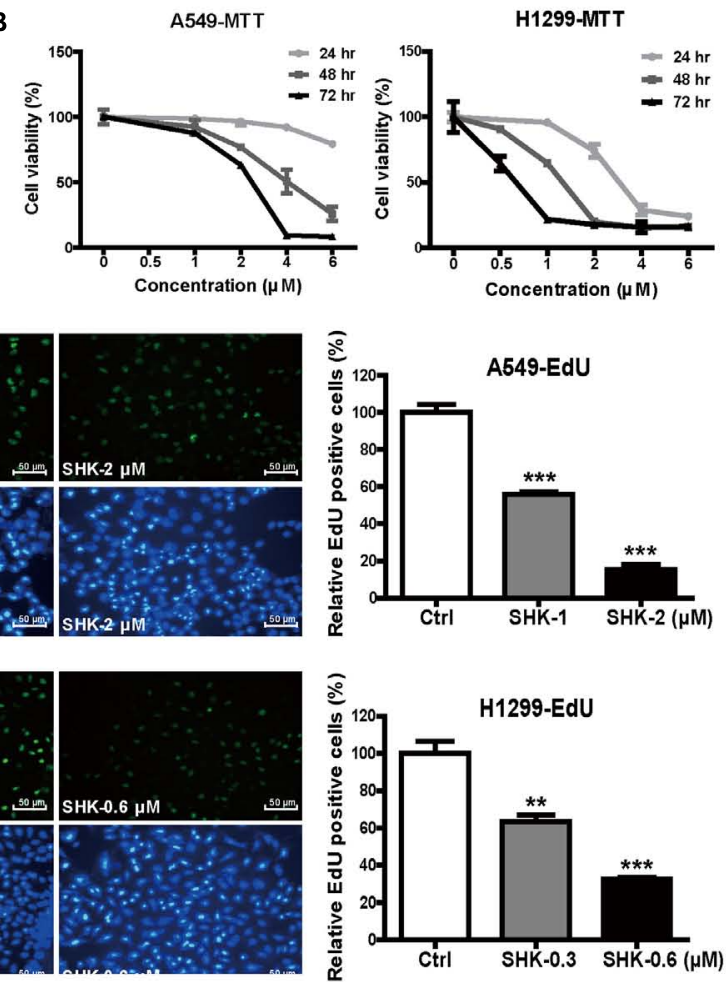

A549-Cell cycle

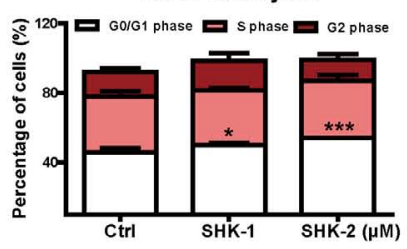

H1299-Cell cycle

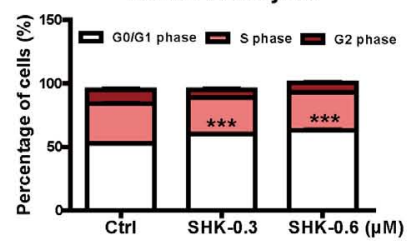

$150 \mathrm{~K} 200 \mathrm{~K} 250 \mathrm{~K}$
G1: $63.37 \%$ S: $29.27 \%$
G2: $7.9 \%$

20

$\mathrm{M}$ PI-A

E

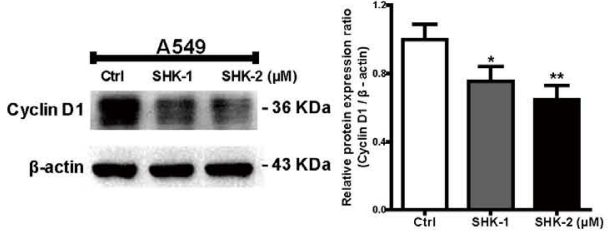

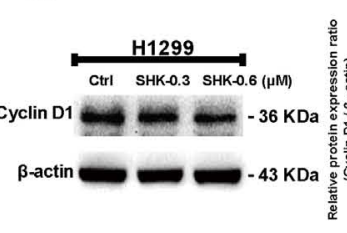

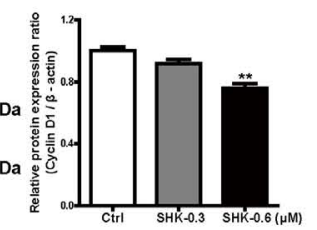

FIGURE 1 | Effects of SHK on cell proliferation and cell cycle arrest. (A) Chemical structure of SHK (MW = 288.3). (B) Cell viabilities of A549 and H1299 cells were measured by MTT assay after treatment with SHK (0-6 $\mu \mathrm{M})$ for 24, 48, and $72 \mathrm{~h}$. (C) EdU incorporation was evaluated after SHK treatments for 72 h, and mean EdU fluorescences in SHK treatments were relative to that in control treatment, which was arbitrarily set as 100. (D) Percentages of cell cycle arrest were analyzed by flow cytometry after SHK treatments. (E) Expression of Cyclin D1 in A549 and H1299 cells after SHK treatments. Data represent mean \pm SD ( $n=3$ ). $P<0.05$, ${ }^{* *} P<0.01,{ }^{* * *} P<0.001$ vs. Ctrl (control).

SAHF, specialized domains of facultative heterochromatin, are predominately contributed to cellular senescence through repressing proliferative-promoting proteins such as cyclin A and D (Banumathy et al., 2009; Litwiniec et al., 2013). To elucidate mechanism underlying the SHK-induced cell cycle arrest observed in Figure 1D, SAHF was detected by confocal microscope. Since most of cellular morphological observation was not closely dependent on dosage, only relative high doses 
of SHK (2 and $0.6 \mu \mathrm{M}$ respectively in A549 and H1299 cells) were used. After treatment with $\mathrm{SHK}$, the chromosomes in control were markedly condensed into numerous SAHF focus. In addition, compared to H1299 cells, SAHF focus was abundantly condensed in A549 cells, suggesting A549 was more sensitive for SHK-induced senescence (Figure 2A). Furthermore, both in A549 and H1299 cells, SHK remarkably altered cellular morphology from spindle and round to flat and enlarged, and the presence of vacuoles were also observed, especially in A549 cells (Figures 2B,C). Meanwhile, the proportions of senescent cells, positively labeled by $\beta$-Gal (Chen et al., 2015), were also gradually increased by SHK (Figure 2C), either in A549 cells (induction ranging from 3.77- to 6.89-fold) $(P<0.001)$ or in H1299 cells (induction ranging from 2.10 - to 4.83 -fold) $(P<0.01$ or $P<0.001)$.

\section{SHK Induced Cellular Senescence Through Stimulating ROS Generation and Subsequently Triggering DNA Damage-p53/p21 waf Axis}

Cellular senescence is predominantly triggered via either oncogenes activation (RAS and $\mathrm{BRAF}^{\mathrm{V} 600 \mathrm{E}}$ ) or depletion of tumor suppressor genes [TSG: PTEN, RB, and CDKN2A (encoding p16 protein)] (Nardella et al., 2011). Herein, to further determine the mechanism underlying SHK-induced cell senescence, Ras, MEK-1, Rb, and p16 expressions were evaluated only in A549 cells due to the abnormal basal expressions of oncogenes and TSG in p53-deleted H1299 cells. Rather than activation, Ras and MEK-1 expressions were unexpectedly decreased by SHK (Figure 3A, $P<0.05$ ), meanwhile, no significant differences were observed on $\mathrm{Rb}$ and $\mathrm{p} 16$ expressions (Figure 3A), suggesting that oncogene and TSG maybe not the main driver factors in SHK-induced senescence.

On the contrary, ROS production was notably increased by SHK (ranging from 0.32- to 3.36-fold in A549 cells and 3.15to 15.31 -fold in H1299 cells) (Figure 3B, $P<0.01$ ). Meanwhile, $\mathrm{Kdm} 2 \mathrm{~b} / \mathrm{JHDM} 1 \mathrm{~b}$, an H3K36me2-specific demethylase involved in cellular senescence, was reported to effectively suppress ROS generation (Polytarchou et al., 2008). After SHK treatment, we found that the expression of $\mathrm{Kdm} 2 \mathrm{~b}$ was significantly decreased in A549 and H1299 cells (Figure 3C, $P<0.01$ ). In contrast, the protein level of $\mathrm{H} 3 \mathrm{~K} 36 \mathrm{me} 2$ was dramatically increased with remarkable inductions (Figure 3C, $P<0.01$ ).

Previous study revealed that ROS contributed to cell senescence through the activation of the $\mathrm{p} 53 / \mathrm{p} 21^{\text {waf }}$ pathway (Adams, 2009). Thus, to further determine the mechanism of SHK-induced senescence and ROS generation, p53 and its downstream target $\mathrm{p} 21^{\text {waf }}$ were evaluated. As shown in Figure 3D, in A549 cells, SHK effectively stimulated p53 transcription, and subsequently induced $\mathrm{p} 21^{\mathrm{waf}}$ expression $(P<0.001)$. Meanwhile, the phosphorylated p53 in nucleus was significantly increased by SHK (Figure 3D, $P<0.01$ ). Whereas, in p53-deleted H1299 cells, the presence of $\mathrm{p} 21^{\text {waf }}$ could alternatively lead to growth arrest and differentiation in a p53-independent manner (Wang et al., 1999). Accordingly, we also observed that SHK at 0.3 and $0.6 \mu \mathrm{M}$ could markedly induced $\mathrm{p} 21^{\text {waf }}$ protein level by 1.76 - and 2.00 -fold, respectively (Figure 3E, $P<0.01$ ). To further confirm the role of $\mathrm{p} 21^{\text {waf }}$ in SHK-induced senescence, p2 $1^{\text {waf }}$ was knock-down in A549 and H1299 cells. The mRNA and protein expressions of $\mathrm{p} 21^{\text {waf }}$ in A549 and H1299 cells were obviously down-regulated by siRNA (Supplementary Figure S1). After siRNA interference, p $21^{\text {waf }}$ expression was remarkably reduced by $71.90 \%$ and $65.52 \%$, respectively, compared to that in SHK treated cells (Figure 3F). Moreover, siRNA interference also significantly reversed SHKinduced senescence in this two cell lines (Figure 3G).

Previous study suggested that after senescence induction, the activation of $\mathrm{p} 53 / \mathrm{p} 21^{\text {waf }}$ pathway was triggered by sever DDR (Dolan et al., 2015). Compared to control treatment, SHK at 1 and $2 \mu \mathrm{M}$ enhanced the expressions of $\mathrm{p}-\mathrm{H} 2 \mathrm{~A}$.X, sensor for DNA damage, by 1.97 - and 3.47-fold, respectively in A549 cells; while that were also increased by 0.3 and $0.6 \mu \mathrm{M}$ of SHK with respective induction of 4.68- and 8.03-fold in H1299 cells (Figure 3H, $P<0.01)$.

\section{SHK-Induced Senescence Was Specifically Dependent on ROS Generation}

To evaluate whether SHK-induced senescence is dependent on ROS, NAC, a classic ROS scavenger was used in our further study. Compared to low intercellular ROS level in control treatment, no significant alteration was observed after treatment with NAC (2 mM). While, NAC pretreatment notably attenuated SHK-induced intracellular ROS generation by $89.55 \% \pm 0.99 \%$ and $75.52 \% \pm 1.35 \%$ in A549 and $\mathrm{H} 1299$ cells, respectively (Figure 4A, $P<0.001$ ).

In contrast to gradually suppressed cell viability in SHK treatments, pretreated with NAC successfully reversed the cytotoxicity of SHK in A549 and H1299 cells in dose-dependent manner (Figure 4B). At the same time, SA- $\beta$-Gal staining results also showed that NAC pretreatment markedly reduced the percentages of SHK-induced senescent cells by $82.64 \% \pm 5.68 \%$ and $73.47 \% \pm 6.63 \%$ in A549 and $\mathrm{H} 1299$ cells, respectively (Figure 4C, $P<0.001)$. And the morphologies of SHK-induced enlarged and flat senescent cells were also effectively reversed by NAC to spindle and round (Figure 4C). Moreover, SHKinduced p53 and p21 waf activation was also completely reversed by pretreated with NAC in A549 cells, as well as that of $\mathrm{p} 21^{\text {waf }}$ activation in $\mathrm{H} 1299$ cells (Figure 4D). Additionally, immunofluorescence results also revealed that both in A549 and H1299 cells, SHK-induced p-H2A.X over-expressions were dramatically diminished by NAC pretreatment (Figure 4E).

\section{SHK-Induced Apoptosis Was Dependent on ROS Generation}

Emerging evidence demonstrated that cytotoxic chemotherapeutic agents simultaneously stimulated a robust cellular senescence to achieve "synthetic senescent interaction," but the extent of senescence and apoptosis is unknown (Collado et al., 2007). Meanwhile, previous study also revealed that apoptosis is the ultimate biological consequence for senescent cells in vivo (Baker et al., 2011). Thus, apoptosis ratio was 
A $\mathbf{A 5 4 9}$

DAPI
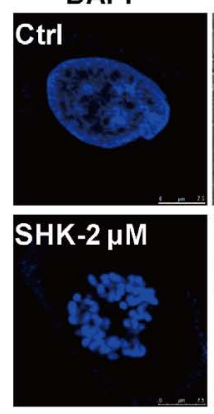

$\mathrm{BF}$
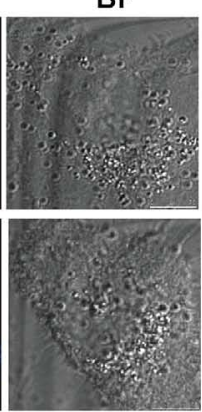

\section{Merge}
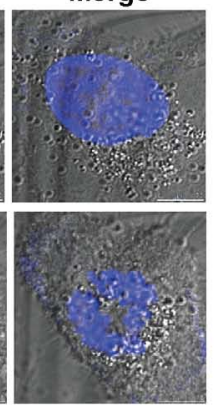

H1299

DAPI
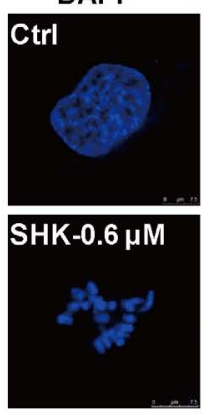

BF
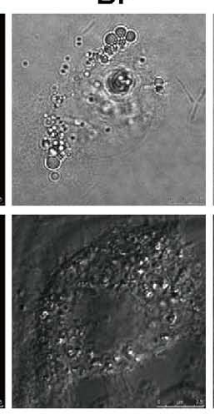

Merge

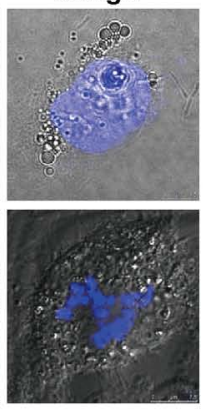

\section{A549}

B

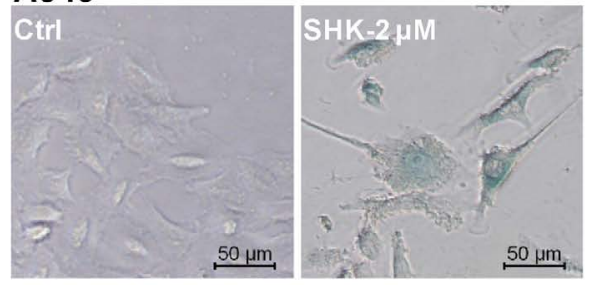

H1299

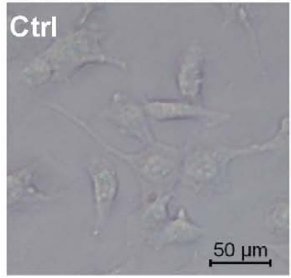

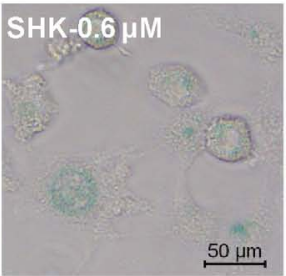

C
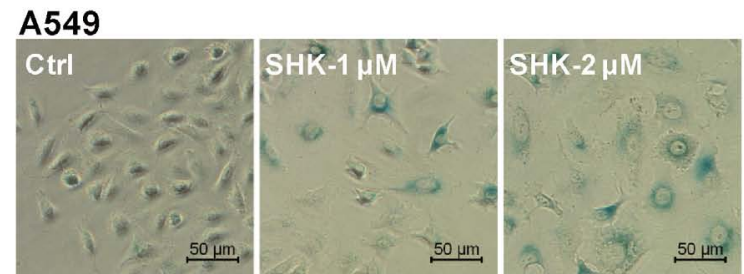

H1299
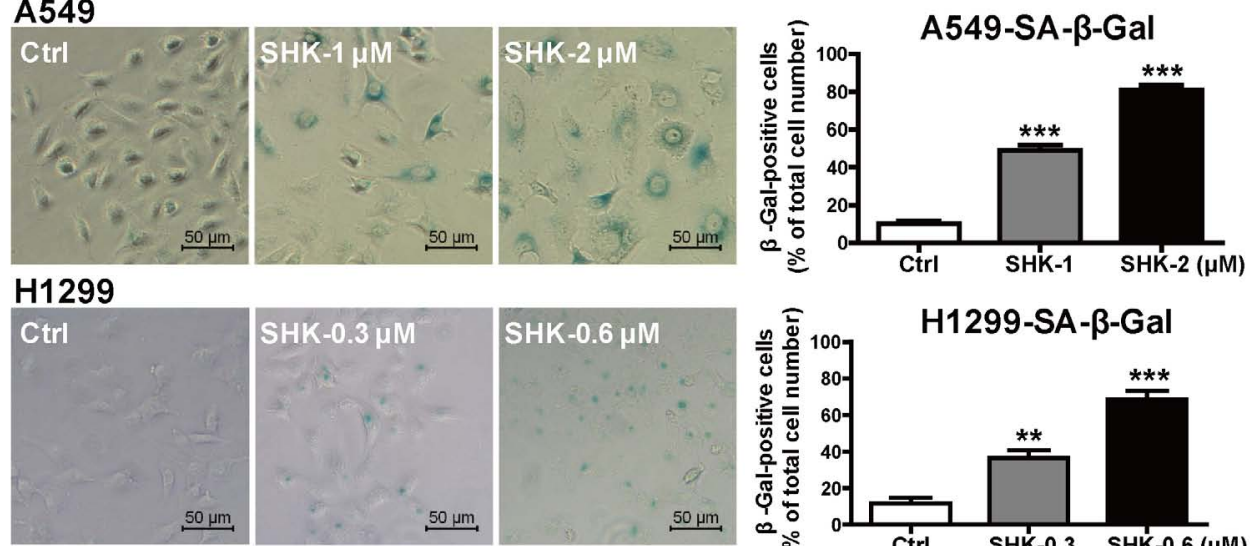

H1299-SA- $\beta-G a l$

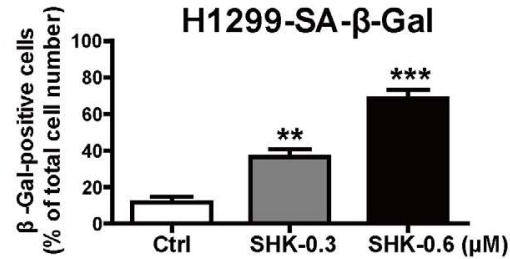

FIGURE 2 | SHK induced senescence in A549 and H1299 cells. (A) Representative confocal imaging (scale bar: 7.5 ㅆm) of SAHF in A549 and H1299 cells after SHK treatment using DAPI (blue) staining. (B) Morphologic changes of A549 and H1299 cells were observed after SHK treatment. (C) The proportions of senescence A549 and H1299 cells were determined using SA- $\beta$-Gal staining after SHK treatments. ${ }^{* * P}<0.01$, ${ }^{* * * P}<0.001$ vs. Ctrl (control).

analyzed subsequently in A549 cells, which were more sensitive toward SHK-induced senescence (Figures 2A-C). Compared to control treatment, SHK significantly increased early and late phases of apoptosis, especially SHK at $2 \mu \mathrm{M}$ induced that by 4.55 - and 3.96-fold, respectively (Figure 5A, $P<0.001$ ). However, compared to the significantly stimulated senescence in A549 cell (range 38.70\%-70.69\%, Figure 2C), the percentage of total apoptosis is extremely low (range 3.13\%-7.65\%, Figure 5A). These implied that rather than apoptosis, the predominant effect of SHK on LAC cells was stimulating senescence.

Moreover, western blot results also showed that compared with control treatment, SHK markedly decreased the expression of anti-apoptosis protein $\mathrm{Bcl}-2$, while that of pro-apoptotic
Bax and Cleaved Caspase-3 were significantly increased. Meanwhile, SHK simultaneously decreased Bcl-2/Bax ratio, a parameter determined the susceptibility of cellular apoptosis, by $43.35 \% \pm 2.60 \%$ and $67.74 \% \pm 2.42 \%$, respectively (Figure 5B, $P<0.001)$. Moreover, NAC pretreatment significantly diminished SHK-induced apoptosis from $8.87 \% \pm 1.17 \%$ to $2.70 \% \pm 0.17 \%$ in A549 cells (Figure 5C, $P<0.001$ ).

\section{SHK Suppressed Lung Cancer Growth in NSCLC Xenograft Mice Models}

To further determine the anti-tumor effect of SHK-induced senescence, A549 xenograft model was established. Afatinib, 
A

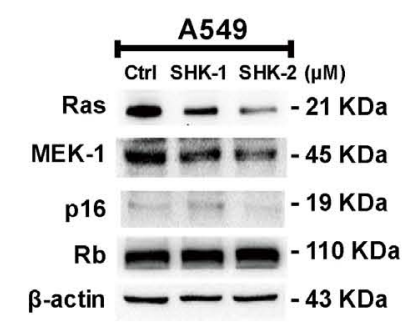

B $\quad$ A549

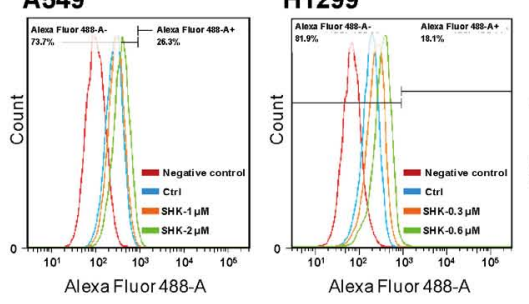

C

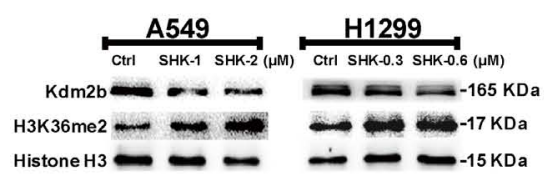

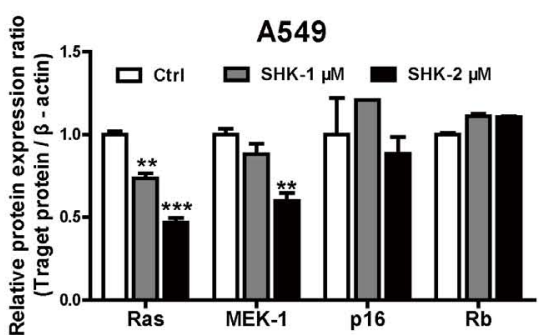
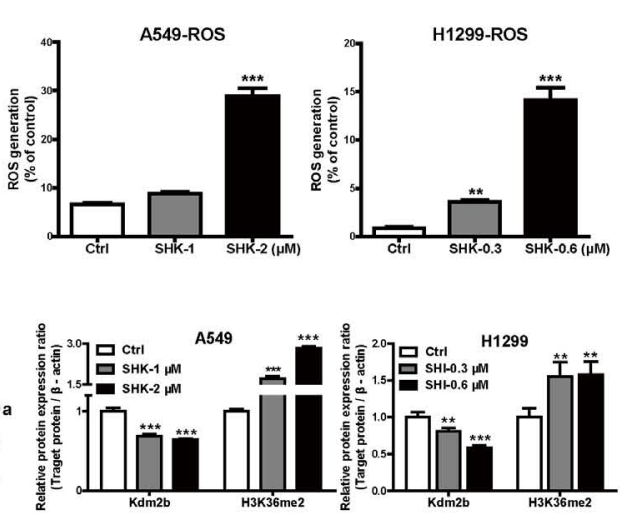

D

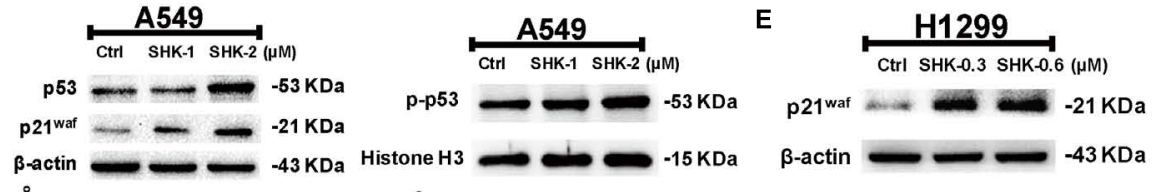

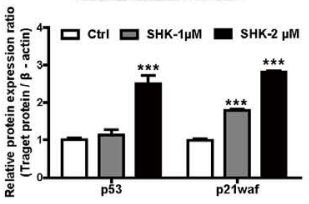
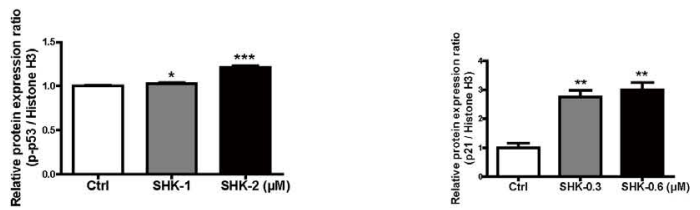

$\mathbf{F}$

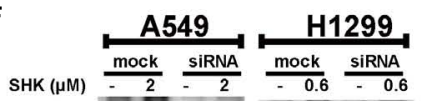

G SHK (HM) $\frac{\text { mock }}{2} \frac{\text { SiRNA }}{2} \frac{\text { mock }}{-0.6} \frac{\text { SiRNA }}{-0.6}$

p21 wat

$\beta$-actin - - - - - - $43 \mathrm{KDa}$
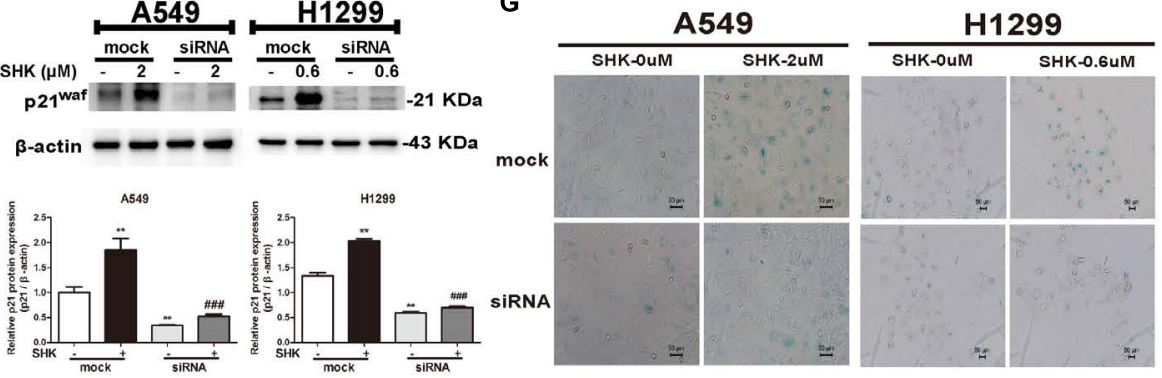

H
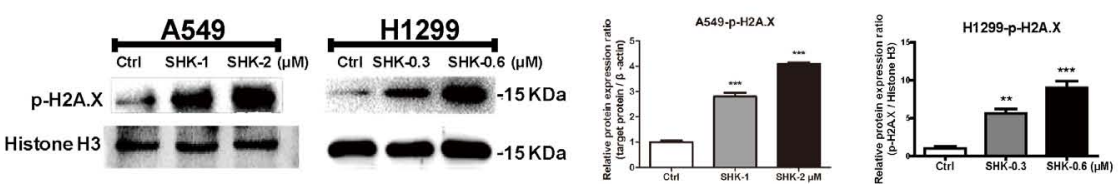

FIGURE 3 | The underlying mechanism of SHK-induced senescence in A549 and H1299 cells. (A) Expressions of Ras, MEK-1, p16 and Rb in A549 cells after SHK treatments. (B) Levels of ROS generation in A549 and H1299 cells were detected by flow cytometry after SHK treatments. (C) Expressions of Kdm2b and H3K36me2 were measured by Western blot after SHK treatments. (D) Expressions of p53 and p21 waf in total protein, and p-p53 in nuclei were determined by Western blot after SHK treatments. (E) Expressions of p21 waf in H1299 cells were measured by Western blot after SHK treatments. (F) Expressions of p21 waf in A549 and H1299 cells transfected with siRNA after SHK treatments. (G) Representative SA- $\beta$-Gal staining imaging (scale bar: $50 \mu \mathrm{m}$ ) of A549 and H1299 cells transfected with siRNA after SHK treatments. (H) Expression of p-H2A.X was inspected by Western blot after SHK treatments. ${ }^{*} P<0.05,{ }^{* *} P<0.01,{ }^{* * *} P<0.001$ vs. Ctrl (control), ${ }^{\# \# \# ~} P<0.001$ vs. SHK. 
A
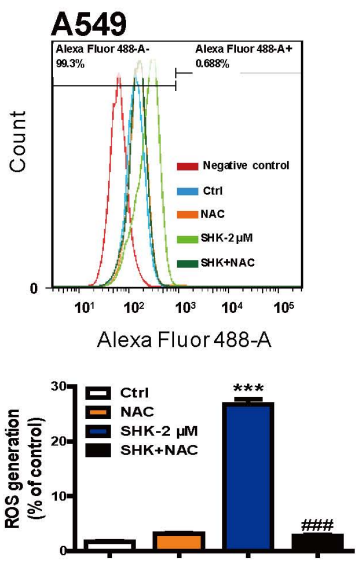

\section{A549}

C
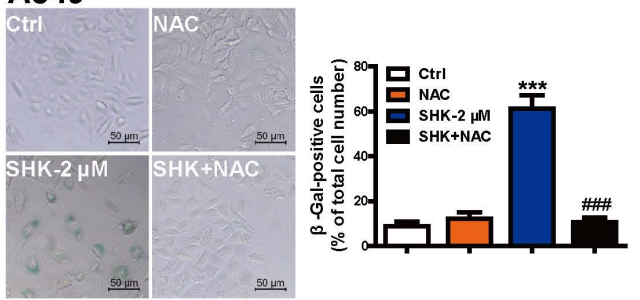
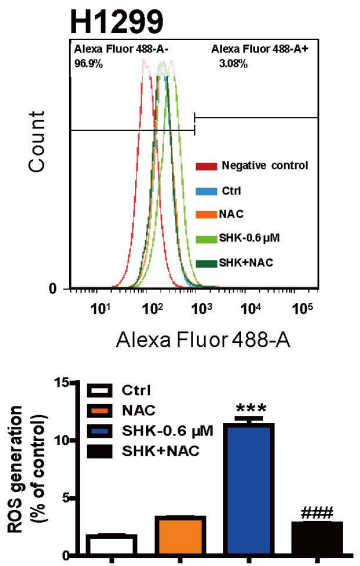

B

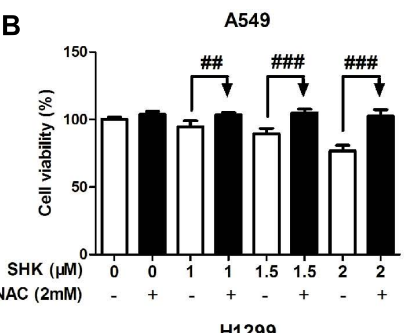

H1299

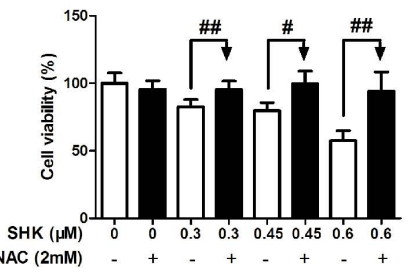

H1299
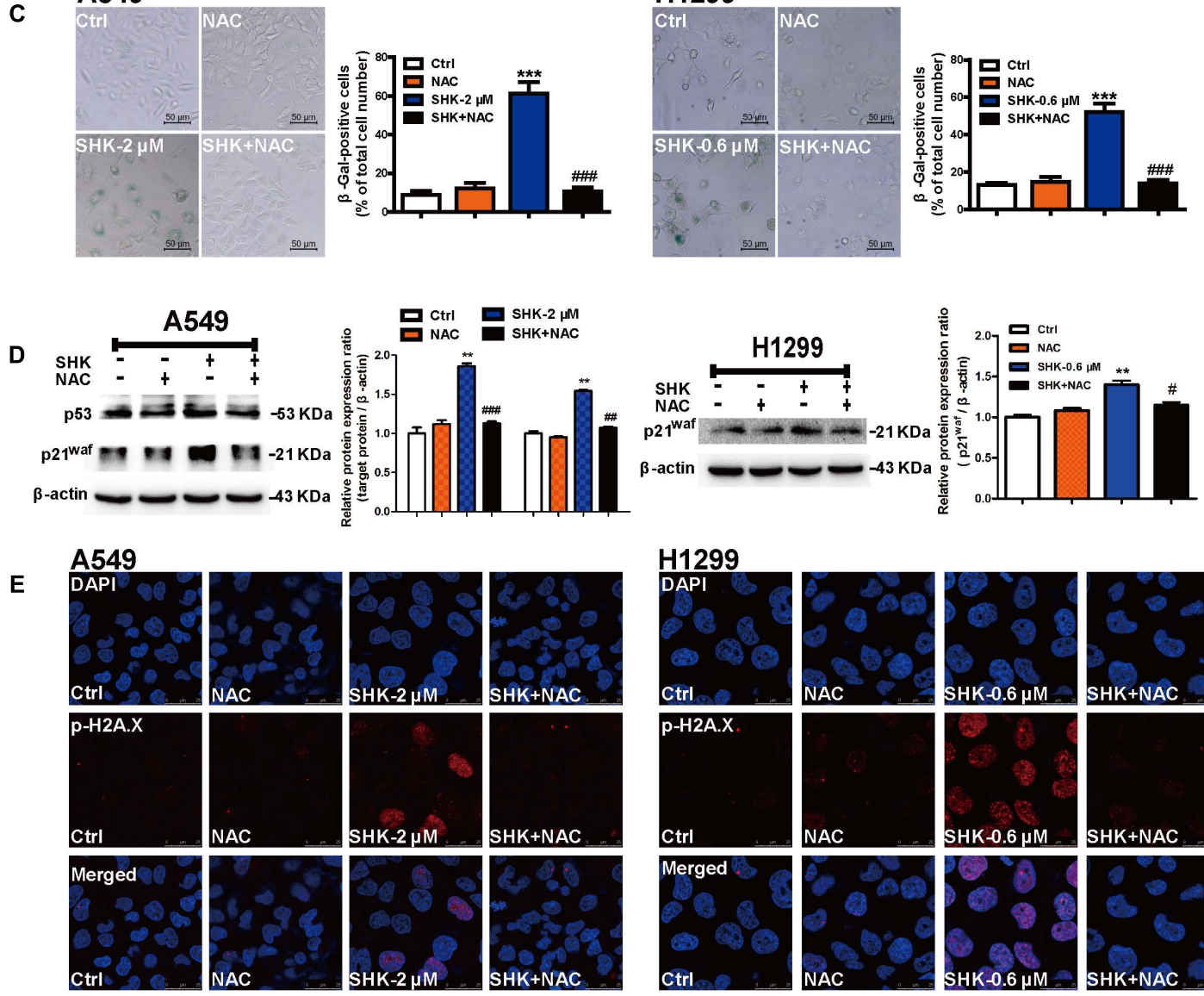

H1299
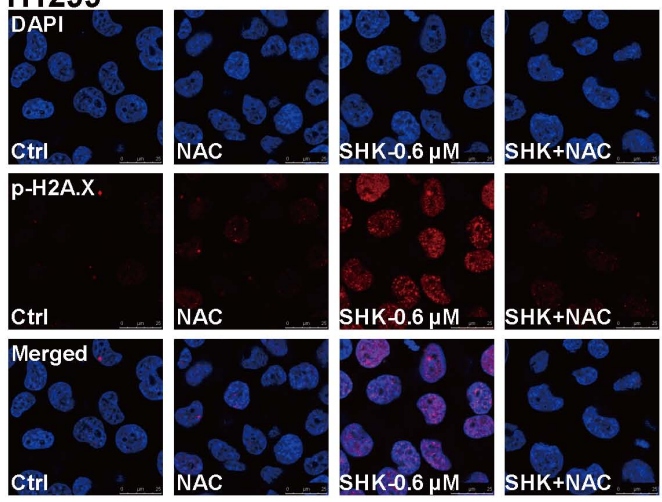

FIGURE 4 | SHK-induced senescence is specifically dependent on ROS generation. (A) ROS generations in A549 and H1299 cells were detected by flow cytometry after $1 \mathrm{~h}$ of NAC (2 mM) pretreatment and $72 \mathrm{~h}$ of SHK treatment. (B) Cell viabilities of A549 and H1299 were determined in the presence of $2 \mathrm{mM}$ NAC pretreatment for $1 \mathrm{~h}$. (C) The proportions of senescence A549 and $\mathrm{H} 1299$ cells were determined using SA- $\beta$-Gal staining after NAC pretreatment and SHK treatment.

(D) Expressions of p53 and p2 $1_{\text {waf }}$ in A549 cells, and expression of p2 1 waf in $\mathrm{H} 1299$ cells were detected by Western blot after NAC pretreatment and SHK treatment. (E) Representative confocal imaging (scale bar: $25 \mu \mathrm{m}$ ) of double-stained cells after NAC pretreatment and SHK treatment using p-H2A.X (red) and DAPI

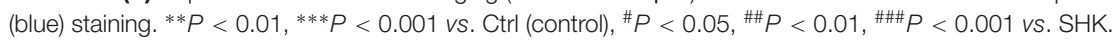

a tyrosine kinase inhibitor normally used as a first-line chemotherapeutic agent for LAC, was reported to induce irreversible senescence to substantially suppress tumor progression (Mcdermott et al., 2016). Given SHK is supposed to be a good senescence-targeting agent in our study, afatinib was used as positive control. After orally gavage SHK and 
A
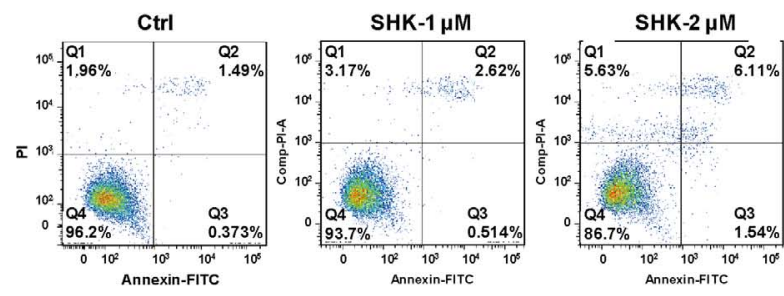

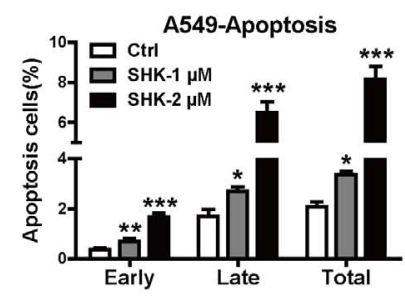

B
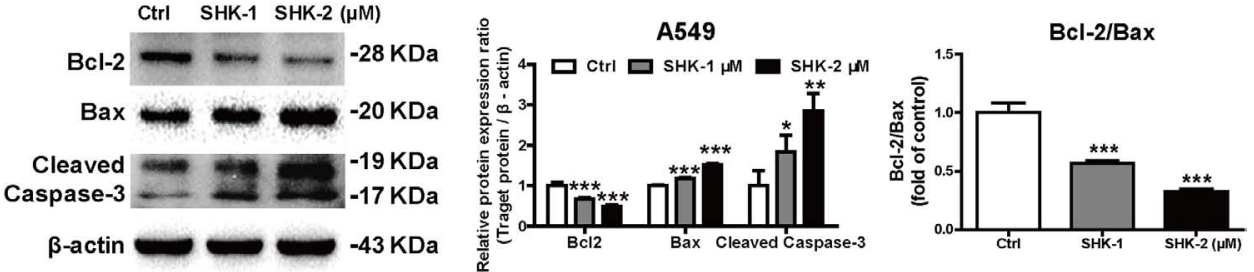

C
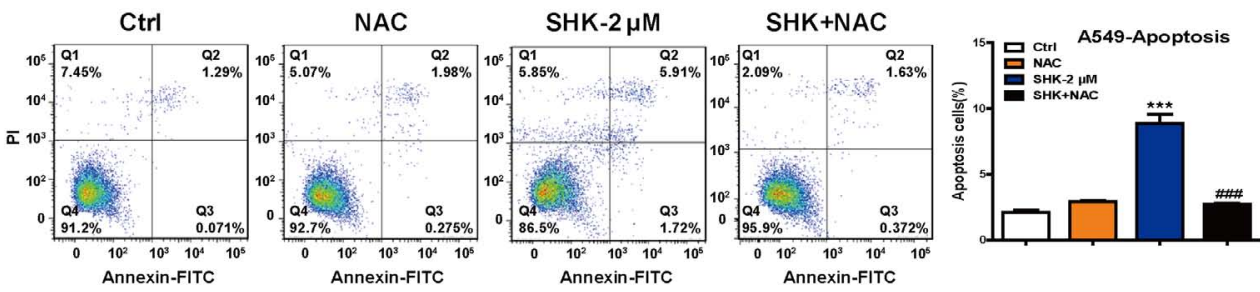

FIGURE 5 | SHK-induced apoptosis depending on ROS generation. (A) The proportions of apoptosis cells of A549 were determined by flow cytometry using FITC annexin V/PI double staining assay after SHK treatments. (B) Expressions of Bcl-2, Bax and Cleaved Caspase-3 were measured by Western blot after SHK treatments. (C) The proportions of apoptosis cells of A549 were determined by flow cytometry after NAC pretreatment and SHK treatment using FITC annexin V/PI double staining assay. ${ }^{*} P<0.05,{ }^{* *} P<0.01,{ }^{* * *} P<0.001$ vs. Ctrl (control), ${ }^{\# \# \#} P<0.001$ vs. SHK.

afatinib for 4 weeks, no significant alterations on average body weight were observed among treatments (Figure 6A). Meanwhile, compared to control treatment (Corn oil), SHK, either at $5 \mathrm{mg} / \mathrm{kg}$ or at $10 \mathrm{mg} / \mathrm{kg}$, did not remarkably alter the tissue indexes including heart, liver, spleen, lung, and kidney (Supplementary Figure S2A), suggesting no systemic toxicity was observed after SHK treatments.

Notably, SHK dose-dependently suppressed tumor growth (Figure 6B), tumor size and tumor weight (Figure 6C). Meanwhile, compared to control, SHK at $5 \mathrm{mg} / \mathrm{kg}$ and $10 \mathrm{mg} / \mathrm{kg}$ also significantly decreased the tumor weights by $28.57 \%$ and $55.84 \%$, respectively (Figure 6C and Table 1, $P<0.05$ ).

To evaluate whether the anti-tumor effect of SHK ascribe to senescence induction, cellular senescence, and the expressions of DNA damage sensor p-H2A.X, p53 and p21 waf were detected in tumor tissues. Compared to control treatment, SHK treatments dramatically increased the percentages of $\beta$-Galpositive senescent cells in tumor tissues (Figure 6D). In addition, the expressions of p-H2A.X, p53 and p2 $1^{\text {waf }}$ were also remarkably increased by SHK in a dose-dependent manner (Figure 6E).

Since p53-deleted H1299 cells is more sensitive than A549 cells to SHK (Figure 1B), we also evaluate the anti-tumor effects of SHK in vivo using H1299 xenograft model. Similar to the results in A549 xenograft model, SHK could effectively suppress tumor volume and tumor weight in H1299 xenograft mice model (Figures 7A,B). Compared to control treatment,
$10 \mathrm{mg} / \mathrm{kg}$ of SHK remarkably inhibited tumor weights by $50.98 \%$. Meanwhile, SHK treatment markedly increased the percentages of $\beta$-Gal-positive senescent cells in tumor tissues (Figure 7C). In addition, the expressions of $\mathrm{p}-\mathrm{H} 2 \mathrm{~A} . \mathrm{X}$ and $\mathrm{p} 21^{\text {waf }}$ were also remarkably increased by SHK treatment (Figure 7D). No changes of the organ (heart, liver, spleen, lung, and kidney) indexes were found in all mice (Supplementary Figure S2B). H\&E staining results also showed that no pathologic changes were observed in organs (heart, liver, and kidney) (Supplementary Figure S2C). These results suggested SHK could suppress lung tumorigenesis through stimulating cellular senescence.

\section{DISCUSSION}

In our study, the anti-tumor effect of SHK was determined and the senescence-involved mechanism was subsequently evaluated. We found that rather than inducing apoptosis, SHK predominantly stimulated cellular senescence via triggering DNA damage-p53/p2 $1^{\text {waf }}$ axis. Moreover, SHK-induced senescence is closely dependent on intercellular ROS accumulation without activating oncogenes or suppressing TSG. Previous study demonstrated that cellular senescence activation could result in apparently opposite outcomes with either tumor suppressive or promoted effects in tumor initiation and progression (Rodier and Campisi, 2011). While the pro-senescence effect of SHK 
A

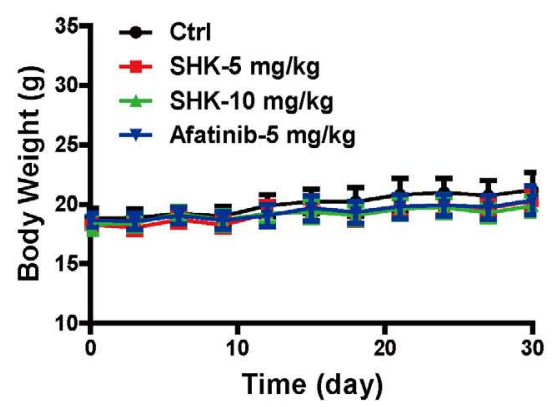

C

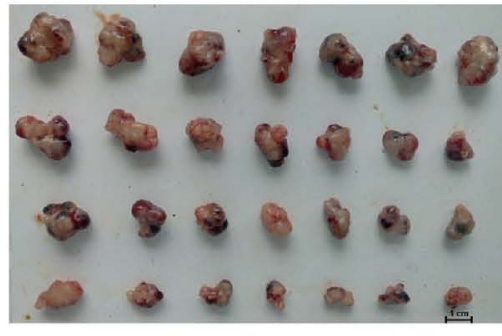

SA- $\beta-G a l$
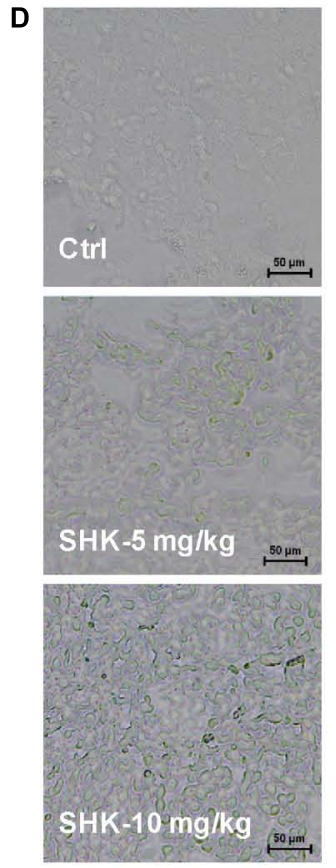

p-H2A.X
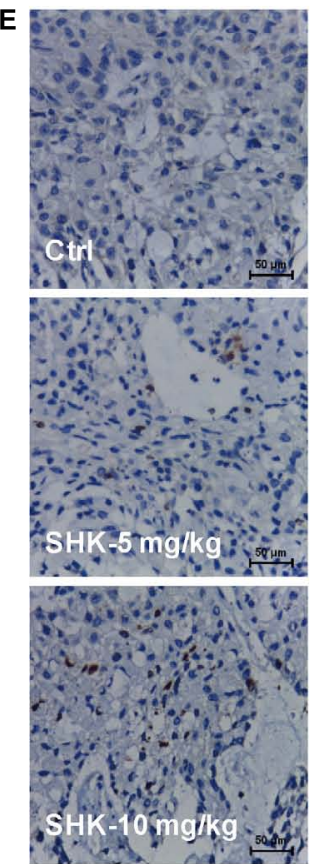

B

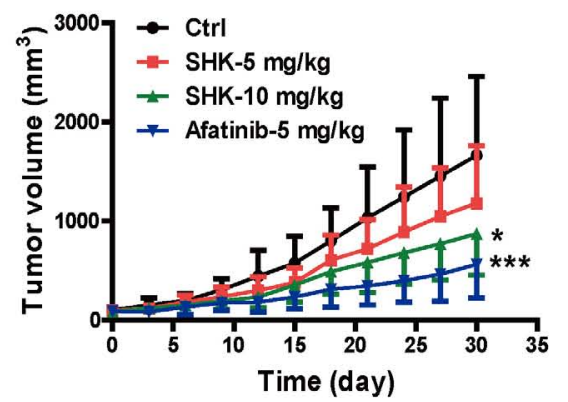

Ctrl

SHK-5 mg/kg

SHK-10 mg/kg

Afatinib-5 mg/kg

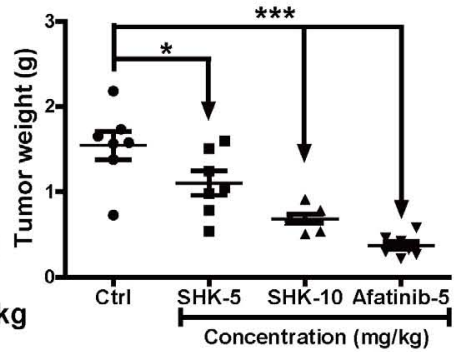

p53
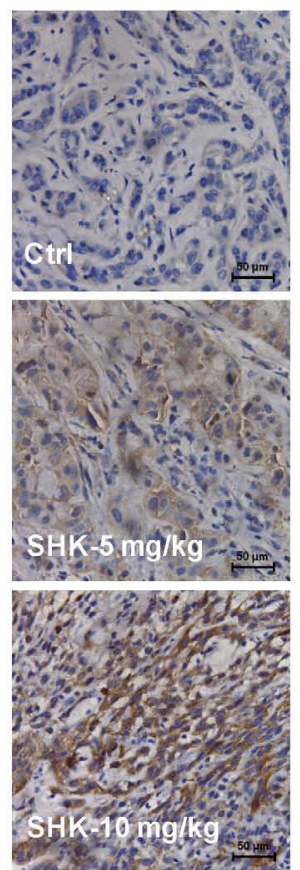

p21 waf

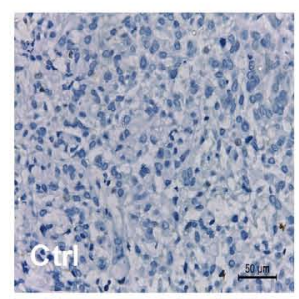

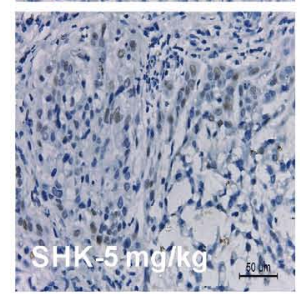

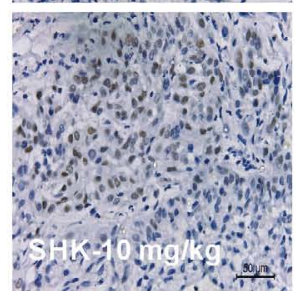

FIGURE 6 | Inhibitory effects of SHK in A549 xenograft mice model. (A) Average body weight curves of Balb/c-nude mice $(n=7)$. (B) Tumor volume ((L $\left.\times W^{2}\right) / 2, L$, long diameter; W, wide diameter) were analyzed. (C) Tumors were photographed and tumor weights were analyzed. (D) Images of senescence cells in tumor consecutive frozen sections using SA- $\beta$-Gal staining assay (scale bar: $50 \mu \mathrm{m}$ ). (E) Images of tumor p-H2A.X, p53 and p21waf protein expressions were presented by immunohistochemistry (scale bar: $50 \mu \mathrm{m}) . *{ }^{*} P<0.05,{ }^{* * *} P<0.001 \mathrm{vs}$. Ctrl (control).

$(10 \mathrm{mg} / \mathrm{kg})$ led to strong tumor inhibition in vivo $(55.84 \%$ in A549 xenograft mice, and 50.98\% in H1299 xenograft mice, respectively), meanwhile, cell cycle, EdU, and apoptosis assays also revealed that SHK notably arrested cell proliferation and activated cellular apoptosis simultaneously. Wild-type p53 is a sequence-specific transcription factor that activates the transcription of downstream effector genes such as p21 et al., thereby preventing the transition from the G1 to the $\mathrm{S}$ phase of 
TABLE 1 | The inhibitory effects of SHK on A549 xenograft mice.

\begin{tabular}{|c|c|c|c|c|c|c|}
\hline Groups & Dose (mg/kg) & Routes & Numbers & Body weight (g) & Tumor weight (g) & Inhibitory rate (\%) \\
\hline Control & Corn oil & p.o.(qd) & $7 / 7$ & $21.2 \pm 1.46$ & $1.54 \pm 0.44$ & \\
\hline SHK & 5 & p.o.(qd) & $7 / 7$ & $20.3 \pm 0.8$ & $1.10 \pm 0.38$ & 28.57 \\
\hline SHK & 10 & p.o.(qd) & $7 / 7$ & $19.9 \pm 0.86$ & $0.68 \pm 0.14$ & 55.84 \\
\hline Afatinib & 5 & p.o.(qd) & $7 / 7$ & $20.3+1.22$ & $0.37 \pm 0.13$ & 75.97 \\
\hline
\end{tabular}

A

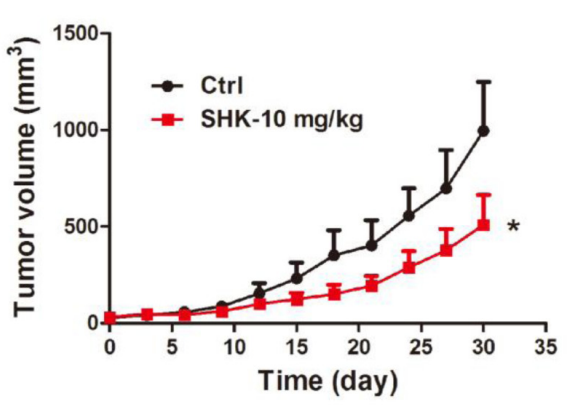

B

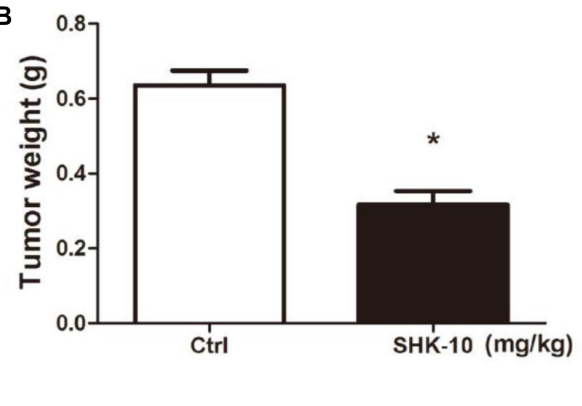

C
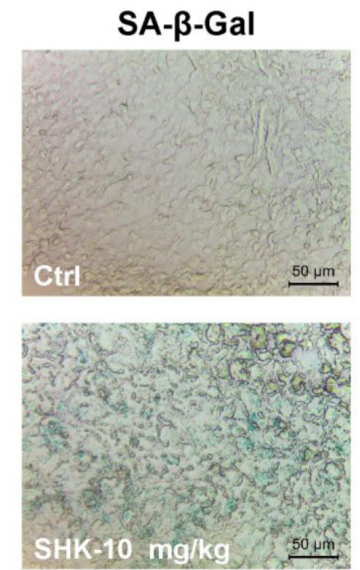

D
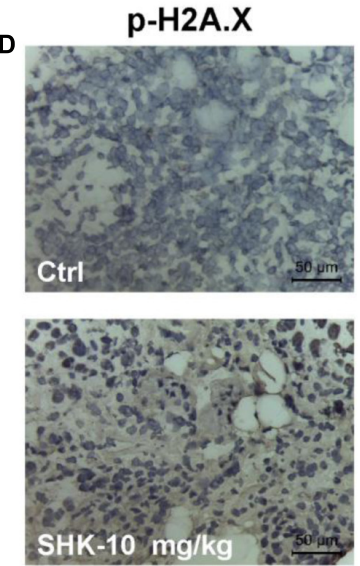

p21waf
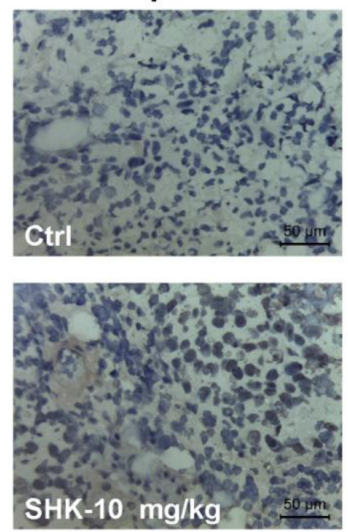

FIGURE 7 | Anti-tumor effects of SHK in H1299 xenograft mice model. (A) Tumor volumes were analyzed. (B) Tumor weights were analyzed. (C) Images of senescence cells in tumor consecutive frozen sections using SA- $\beta$-Gal staining assay (scale bar: $50 \mu \mathrm{m}$ ). (D) Images of tumor p-H2A.X and p21 waf protein expressions were presented by immunohistochemistry (scale bar: $50 \mu \mathrm{m}) .{ }^{*} P<0.05$ vs. Ctrl (control).

cell cycle (Slebos et al., 1994). In our study, besides of stimulating the expression and phosphorylation of p53, SHK also notably increased the percentage of A549 and H1299 cells at G0/G1 phase.

Our study provides additional evidence to complement the correlation between ROS and senescence, and suggested the district mechanism underlying ROS-induced senescence and OIS. Previous study demonstrated that ROS-induced senescence is partially triggered by OIS, intercellular ROS accumulation is ascribe to activation of RAS-RAF-MEK-ERK pathway (MuñozEspín and Serrano, 2014). On the contrary, we found that SHK significantly induced cellular senescence by accelerating ROS generation (Figure 2C) while inactivating oncogenes such as Ras and MEK-1 (Figure 3A), and meanwhile did not altering TSG such as RB (Figure 3A). This may suggest that ROSinduced senescence might be a combination progress of OIS and RS, and oncogene or TSG alterations are not essential driven factors. When ROS scavenger NAC is present, SHK-induced senescence were strongly diminished (Figure 4C), implied that SHK-induced senescence is closely dependent on ROS production than other molecular factors. Additionally, in a good agreement with another study, the negative correlation between ROS and oncogene expressions observed in our study suggested SHK may effectively reversed the overactivated oncogenes in tumors by physiologically enhanced ROS generation (DeNicola et al., 2011). Furthermore, ROS-induced senescence consequently induced DDR, p53, phosphorylated p53, and p2 $1^{\text {waf }}$ (Figures 3D,F), and when ROS is depleted, DDR was subsequently suppressed (Figure 4E). Even in p53depleted H1299 cells, senescence was also effectively stimulated by SHK through basal overexpressed p21 waf (Figure 3E). Moreover, knock-down of $\mathrm{p} 21^{\text {waf }}$ significantly reversed SHKinduced senescence in both A549 and H1299 cells (Figures 3F,G), suggesting despite p53 phosphorylation (Nardella et al., 2011), persistent $\mathrm{p} 21^{\mathrm{waf}}$ activation is the most predominant prerequisite 
for ROS-induced senescence. Taken previous reports and our findings together may inform the further study on ROSinduced senescence in following aspects: (i) ROS-dependent senescence, not relay on oncogenes activation, is partially district from OIS, some alternative mechanism may underlying and need extensively investigation; (ii) p53 activation and phosphorylation could promote ROS-induced senescence, while p $21^{\text {waf }}$ overexpression is the predominant driver.

Our findings uncovered the proportion and predominant role of senescence and apoptosis involved in anti-tumor effects of SHK. Although the concept of "senescence" is firstly found in 1965 by Leonard Hayflick, the usage of it as a cancer therapy strategy is underestimated and little excited pro-senescence agents were discovered (Petrova et al., 2016). This may partially due to the concerns of whether the senescent cells will relay on anti-apoptosis pathway to persist in tissues? And how the senescent cells will be cleaned up? We found that SHK significantly induced senescence and apoptosis at the same time (Figures 2, 5). While compared to the abundantly stimulated senescence in A549 cell (range 38.70\%-70.69\%, Figure 2C), the percentage of total apoptosis is extremely low (range 3.13\%$7.65 \%$, Figure 5A), which implied that rather than apoptosis, the predominant mechanism responsible for the anti-tumor effect of SHK was ascribed to senescence stimulation. Meanwhile, SHK markedly decreased anti-apoptosis protein Bcl-2 while increased pro-apoptotic Bax (Figure 5B), suggested that SHKinduced senescent cells could be further and gradually cleaned up by SHK-induced apoptosis. Other studies also revealed that senescence stimulate immunosurveillance to eliminate tumor cells (Coppé et al., 2009; Rakhra et al., 2010), therefore, the effects of SHK on immune cells such as natural killer cells, T, B, and macrophages need to be further determined. Furthermore, compared to cytotoxic chemotherapeutic agents such as doxorubicin, vincristine, and cyclophosphamide, the pro-senescence agents could provide an alternative opportunity to avoid systemic toxicities by stimulating intrinsic anti-tumor response (Venturelli et al., 2013). In xenograft model, we also observed that SHK-induced senescence remarkably suppressed tumor growth without altering body weight during 4 weeks of treatment (Figures 6A). Moreover, No changes of the organ (heart, liver, spleen, lung, and kidney) indexes were found in all mice, and no pathologic changes were observed in organs (heart, liver, and kidney) (Supplementary Figure S2), suggesting no observed systemic toxicities were induced by SHK.

Taken together, by determining the pro-senescence mechanism of SHK in lung cancer cells, our present study advances our understanding of ROS-induced senescence and the anti-tumor effect of SHK in following aspects: (i) ROSdependent senescence, not relay on oncogenes activation, is partially district from OIS, which implied that some alternative mechanisms may underlying and need extensively

\section{REFERENCES}

Acosta, J. C., and Gil, J. (2012). Senescence: a new weapon for cancer therapy. Trends Cell Biol. 22, 211-219. doi: 10.1016/j.tcb.2011. 11.006 investigation; (ii) p53 activation and phosphorylation could promote ROS-induced senescence, while $\mathrm{p} 21^{\text {waf }}$ overexpression might be the predominant driver; (iii) SHK may predominantly stimulate ROS-dependent senescence, while simultaneously accelerate cellular apoptosis program to eliminate the senescent tumor cells. The subsequently triggered pro-apoptosis pathway laid foundation to the further regard SHK as promising anti-tumor agents. However, considering the low proportion of apoptosis induced by SHK, other cleaned up mechanisms such as immunosurveillance, autophagy, and necrosis need to be further determined on SHK-induced senescence.

\section{CONCLUSION}

SHK could induce cellular senescence through stimulating ROS generation and subsequently triggering DNA damagep53/p2 $1^{\text {waf }}$ axis. SHK, a ROS-dependent senescence inducer, could serve as a promising agent for further lung cancer treatment.

\section{AUTHOR CONTRIBUTIONS}

$\mathrm{LL}$ and $\mathrm{ZL}$ designed the research. $\mathrm{HZ}, \mathrm{QH}$, and $\mathrm{ScH}$ performed the study. LL, HZ, QH, and $\mathrm{ScH}$ analyzed the data, wrote and revised the manuscript. XY, TZ, WW, HW, SgH, LJ, YW, and XQ provided some technical support. All the authors are accountable for the content of the work.

\section{FUNDING}

This work was mainly supported by Guangdong Natural Science Foundation Province (2015A030312012, 2016A050502052, and 2014A020221076), the Science and Technology Development of Guangzhou city (201509010004), and Traditional Chinese Medicine Bureau of Guangdong Province.

\section{ACKNOWLEDGMENTS}

We would like to thank professor Ah-Ng Tony Kong for technical assistance.

\section{SUPPLEMENTARY MATERIAL}

The Supplementary Material for this article can be found online at: https://www.frontiersin.org/articles/10.3389/fphar. 2018.00519/full\#supplementary-material

Adams, P. D. (2009). Healing and hurting: molecular mechanisms, functions, and pathologies of cellular senescence. Mol. Cell 36, 2-14. doi: 10.1016/j.molcel. 2009.09.021

Baker, D. J., Wijshake, T., Tchkonia, T., Lebrasseur, N. K., Childs, B. G., Van De, S. B., et al. (2011). Clearance of p16Ink4a-positive senescent cells delays 
ageing-associated disorders. J. Agric. Biotechnol. 479, 232-236. doi: 10.1038/ nature 10600

Banumathy, G., Somaiah, N., Zhang, R., Tang, Y., Hoffmann, J., Andrake, M., et al. (2009). Human UBN1 is an ortholog of yeast Hpc2p and has an essential role in the HIRA/ASF1a chromatin-remodeling pathway in senescent cells. Mol. Cell. Biol. 29, 758-770. doi: 10.1128/MCB.01047-08

Burchett, K. M., Yan, Y., and Ouellette, M. M. (2014). Telomerase inhibitor Imetelstat (GRN163L) limits the lifespan of human pancreatic cancer cells. PLoS One 9:e85155. doi: 10.1371/journal.pone.0085155

Campaner, S., Doni, M., Hydbring, P., Verrecchia, A., Bianchi, L., Sardella, D., et al. (2010). Cdk2 suppresses cellular senescence induced by the c-myc oncogene. Nat. Cell Biol. 12, 54-59. doi: 10.1038/ncb2004

Chen, X., Yang, L., Oppenheim, J. J., and Howard, M. Z. (2002). Cellular pharmacology studies of shikonin derivatives. Phytother. Res. 16, 199-209. doi: 10.1002/ptr.1100

Chen, Y., Yang, L., Cui, T., Pacyna-Gengelbach, M., and Petersen, I. (2015). HOPX is methylated and exerts tumour-suppressive function through Ras-induced senescence in human lung cancer. J. Pathol. 235, 397-407. doi: 10.1002/path. 4469

Collado, M., Blasco, M. A., and Serrano, M. (2007). Cellular senescence in cancer and aging. Cell 130, 223-233. doi: 10.1016/j.cell.2007.07.003

Collado, M., Gil, J., Efeyan, A., Guerra, C., Schuhmacher, A. J., Barradas, M., et al. (2005). Tumour biology: senescence in premalignant tumours. Nature 436:642. doi: 10.1038/436642a

Coppé, J. P., Patil, C. K., Rodier, F., Sun, Y., Muñoz, D. P., Goldstein, J., et al. (2009). Senescence-associated secretory phenotypes reveal cell-nonautonomous functions of oncogenic RAS and the p53 tumor suppressor. PLoS Biol. 6, 2853-2868. doi: 10.1371/journal.pbio.0060301

Curado, M. P., Edwards, B., Shin, H. R., Storm, H., Ferlay, J., Heanue, M., et al. (2008). Cancer Incidence in Five Continents, Vol. IX. Lyon: International Agency for Research on Cancer.

David, G. (2012). Regulation of oncogene-induced cell cycle exit and senescence by chromatin modifiers. Cancer Biol. Ther. 13, 992-1000. doi: 10.4161/cbt. 21116

DeNicola, G. M., Karreth, F. A., Humpton, T. J., Gopinathan, A., Wei, C., Frese, K., et al. (2011). Oncogene-induced Nrf2 transcription promotes ROS detoxification and tumorigenesis. Nature 475, 106-109. doi: 10.1038/ nature 10189

Dimri, G. P., Lee, X., Basile, G., Acosta, M., Scott, G., Roskelley, C., et al. (1995). A biomarker that identifies senescent human cells in culture and in aging skin in vivo. Proc. Natl. Acad. Sci. U.S.A. 92, 9363-9367. doi: 10.1073/pnas.92.20. 9363

Dolan, D. W., Zupanic, A., Nelson, G., Hall, P., Miwa, S., Kirkwood, T. B., et al. (2015). Integrated stochastic model of DNA damage repair by non-homologous end joining and p53/p21-mediated early senescence signalling. PLoS Comput. Biol. 11:e1004246. doi: 10.1371/journal.pcbi.1004246

Dörr, J. R., Yu, Y., Milanovic, M., Beuster, G., Zasada, C., Däbritz, J. H., et al. (2013). Synthetic lethal metabolic targeting of cellular senescence in cancer therapy. Nature 501, 421-425. doi: 10.1038/nature12437

Ferlay, J., Soerjomataram, I., Dikshit, R., Eser, S., Mathers, C., Rebelo, M., et al. (2015). Cancer incidence and mortality worldwide: sources, methods and major patterns in GLOBOCAN 2012. Int. J. Cancer 136, E359-E386. doi: 10.1002/ijc. 29210

Fertig, E. J., Ozawa, H., Thakar, M., Howard, J. D., Kagohara, L. T., Krigsfeld, G., et al. (2016). CoGAPS matrix factorization algorithm identifies transcriptional changes in AP-2alpha target genes in feedback from therapeutic inhibition of the EGFR network. Oncotarget 7, 73845-73864. doi: 10.18632/ oncotarget. 12075

Funayama, R., Saito, M., Tanobe, H., and Ishikawa, F. (2006). Loss of linker histone H1 in cellular senescence. J. Cell Biol. 175, 869-880. doi: 10.1083/jcb.200604005

Han, S. Y., Ko, A., Kitano, H., Choi, C. H., Lee, M. S., Seo, J., et al. (2017). Molecular chaperone HSP90 is necessary to prevent cellular senescence via lysosomal degradation of p14ARF. Cancer Res. 77, 343-354. doi: 10.1158/00085472.CAN-16-0613

Lan, W., Wan, S., Gu, W., Wang, H., and Zhou, S. (2014). Mechanisms behind the inhibition of lung adenocarcinoma cell by shikonin. Cell Biochem. Biophys. 70, 1459-1467. doi: 10.1007/s12013-014-0083-5

Li, X., Fan, X. X., Jiang, Z. B., Loo, W. T., Yao, X. J., Leung, E. L., et al. (2017). Shikonin inhibits gefitinib-resistant non-small cell lung cancer by inhibiting
TrxR and activating the EGFR proteasomal degradation pathway. Pharmacol. Res. 115, 45-55. doi: 10.1016/j.phrs.2016.11.011

Litwiniec, A., Gackowska, L., Helmin-Basa, A., Zuryn, A., and Grzanka, A. (2013). Low-dose etoposide-treatment induces endoreplication and cell death accompanied by cytoskeletal alterations in A549 cells: does the response involve senescence? The possible role of vimentin. Cancer Cell Int. 13:9. doi: 10.1186/ 1475-2867-13-9

Lleonart, M. E., Arterocastro, A., and Kondoh, H. (2009). Senescence induction; a possible cancer therapy. Mol. Cancer 8:3. doi: 10.1186/1476-4598-8-3

Lu, L., Qin, A., Huang, H., Zhou, P., Zhang, C., Liu, N., et al. (2011). Shikonin extracted from medicinal Chinese herbs exerts anti-inflammatory effect via proteasome inhibition. Eur. J. Pharmacol. 658, 242-247. doi: 10.1016/j.ejphar. 2011.02.043

Mcdermott, M., Browne, B., Szabo, A., Crown, J., and O'Donovan, N. (2016). Irreversible panHER tyrosine kinase inhibitors (TKIs) to induce irreversible senescence in HER2 positive breast cancer cells. J. Clin. Oncol. 34(Suppl. 15):e12092. doi: 10.1200/JCO.2016.34.15_suppl.e12092

Muñoz-Espín, D., and Serrano, M. (2014). Cellular senescence: from physiology to pathology. Nat. Rev. Mol. Cell Biol. 15, 482-496. doi: 10.1038/nrm 3823

Nardella, C., Clohessy, J. G., Alimonti, A., and Pandolfi, P. P. (2011). Prosenescence therapy for cancer treatment. Nat. Rev. Cancer 11, 503-511. doi: $10.1038 / \mathrm{nrc} 3057$

Ogrunc, M., Di Micco, R., Liontos, M., Bombardelli, L., Mione, M., Fumagalli, M., et al. (2014). Oncogene-induced reactive oxygen species fuel hyperproliferation and DNA damage response activation. Cell Death Differ. 21, 998-1012. doi: $10.1038 /$ cdd.2014.16

Petrova, N. V., Velichko, A. K., Razin, S. V., and Kantidze, O. L. (2016). Small molecule compounds that induce cellular senescence. Aging Cell 15, 999-1017. doi: $10.1111 /$ acel.12518

Polytarchou, C., Pfau, R., Hatziapostolou, M., and Tsichlis, P. N. (2008). The JmjC domain histone demethylase Ndyl regulates redox homeostasis and protects cells from oxidative stress. Mol. Cell. Biol. 28, 7451-7464. doi: 10.1128/MCB. 00688-08

Puyol, M., Martin, A., Dubus, P., Mulero, F., Pizcueta, P., Khan, G., et al. (2010). A synthetic lethal interaction between K-Ras oncogenes and Cdk4 unveils a therapeutic strategy for non-small cell lung carcinoma. Cancer Cell 18, 63-73. doi: 10.1016/j.ccr.2010.05.025

Rakhra, K., Bachireddy, P., Zabuawala, T., Zeiser, R., Xu, L., Kopelman, A., et al. (2010). CD4 ${ }^{+} \mathrm{T}$ cells contribute to the remodeling of the microenvironment required for sustained tumor regression upon oncogene inactivation. Cancer Cell 18, 485-498. doi: 10.1016/j.ccr.2010.10.002

Rodier, F., and Campisi, J. (2011). Four faces of cellular senescence. J. Cell Biol. 192, 547-556. doi: 10.1083/jcb.201009094

Shao, L., Wang, Y., Chang, J., Luo, Y., Meng, A., and Zhou, D. (2013). Hematopoietic stem cell senescence and cancer therapy-induced long-term bone marrow injury. Transl. Cancer Res. 2, 397-411. doi: 10.3978/j.issn.2218676X.2013.07.03

Sherr, C. J., and Roberts, J. M. (2004). Living with or without cyclins and cyclin-dependent kinases. Genes Dev. 18, 2699-2711. doi: 10.1101/gad. 1256504

Slebos, R. J., Lee, M. H., Plunkett, B. S., Kessis, T. D., Williams, B. O., Jacks, T., et al. (1994). p53-dependent G1 arrest involves pRB-related proteins and is disrupted by the human papillomavirus 16 E7 oncoprotein. Proc. Natl. Acad. Sci. U.S.A. 91, 5320-5324. doi: 10.1073/pnas.91.12.5320

Tan, W., Gu, Z., Shen, B., Jiang, J., Meng, Y., Da, Z., et al. (2015). PTEN/Akt-p27(kip1) signaling promote the BM-MSCs senescence and apoptosis in SLE patients. J. Cell. Biochem. 116, 1583-1594. doi: 10.1002/jcb. 25112

Venturelli, S., Berger, A., Weiland, T., Essmann, F., Waibel, M., Nuebling, T., et al. (2013). Differential induction of apoptosis and senescence by the DNA methyltransferase inhibitors 5-azacytidine and 5-aza-2'-deoxycytidine in solid tumor cells. Mol. Cancer Ther. 12, 2226-2236. doi: 10.1158/1535-7163.MCT13-0137

Wang, H., Wu, C., Wan, S., Zhang, H., Zhou, S., and Liu, G. (2013). Shikonin attenuates lung cancer cell adhesion to extracellular matrix and metastasis by inhibiting integrin betal expression and the ERK1/2 signaling pathway. Toxicology 308, 104-112. doi: 10.1016/j.tox.2013. 03.015 
Wang, Y., Blandino, G., and Givol, D. (1999). Induced p21waf expression in H1299 cell line promotes cell senescence and protects against cytotoxic effect of radiation and doxorubicin. Oncogene 18, 2643-2649. doi: 10.1038/sj.onc. 1202632

Xie, X., Koh, J. Y., Price, S., White, E., and Mehnert, J. M. (2015). Atg7 overcomes senescence and promotes growth of BrafV600E-driven melanoma. Cancer Discov. 5, 410-423. doi: 10.1158/2159-8290.CD-141473

Yang, S., Luo, A., Hao, X., Lai, Z., Ding, T., Ma, X., et al. (2011). Peroxiredoxin 2 inhibits granulosa cell apoptosis during follicle atresia through the NFKB pathway in mice. Biol. Reprod. 84, 1182-1189. doi: 10.1095/biolreprod.110. 087569

Yeh, Y. C., Liu, T. J., and Lai, H. C. (2015). Shikonin induces apoptosis, necrosis, and premature senescence of human A549 lung cancer cells through upregulation of p53 expression. Evid. Based Complement. Alternat. Med. 2015:620383. doi: 10.1155/2015/620383
Conflict of Interest Statement: The authors declare that the research was conducted in the absence of any commercial or financial relationships that could be construed as a potential conflict of interest.

The authors LL and ZL declared a shared secondary affiliation, though no collaboration with the handling Editor and reviewer WH.

The reviewer WH and handling Editor declared their shared affiliation.

Copyright (c) 2018 Zheng, Huang, Huang, Yang, Zhu, Wang, Wang, He, Ji, Wang, Qi, Liu and $L u$. This is an open-access article distributed under the terms of the Creative Commons Attribution License (CC BY). The use, distribution or reproduction in other forums is permitted, provided the original author(s) and the copyright owner are credited and that the original publication in this journal is cited, in accordance with accepted academic practice. No use, distribution or reproduction is permitted which does not comply with these terms. 